

\section{A}

\section{Enfoque y alcance}

La Revista de Arquitectura (ISSN 1657-0308 Impresa y E-ISSN 2357-626X en línea) es una publicación seriada de acceso abierto, arbitrada mediante revisión por pares (doble ciego) e indexada, en donde se publican resultados de investigación originales e inéditos.

Está dirigida a la comunidad académica y profesional de las áreas afines a la disciplina. Es editada por la Facultad de Diseño y el Centro de Investigaciones (CIFAR) de la Universidad Católica de Colombia en Bogotá (Colombia).

La principal área científica a la que se adscribe la Revista de Arquitectura según la OCDE es:

Gran área: 6. Humanidades

Área: 6.D. Arte

Disciplina: 6D07. Arquitectura y Urbanismo

También se publican artículos de las disciplinas como 2A02, Ingeniería arquitectónica; 5G03, Estudios urbanos (planificación y desarrollo); 6D07, Diseño.

Los objetivos de la Revista de Arquitectura son:

- Promover la divulgación y difusión del conocimiento generado a nivel local, nacional e internacional

- Conformar un espacio para la construcción de comunidades académicas y la discusión en torno a las secciones definidas.

- Fomentar la diversidad institucional y geográfica de los autores que participan en la publicación.

- Potenciar la discusión de experiencias e intercambios científicos entre investigadores y profesionales.

- Contribuir a la visión integral de la arquitectura, por medio de la concurrencia y articulación de las secciones mediante la publicación de artículos de calidad.

- Publicar artículos originales e inéditos que han pasado por revisión de pares, para asegurar que se cumplen las normas éticas, de calidad, validez científica, editorial e investigativa.

- Fomentar la divulgación de las investigaciones y actividades desarrolladas en la Universidad Católica de Colombia.
Palabras clave de la Revista de Arquitectura: arquitectura, diseño, educación arquitectónica, proyecto y construcción, urbanismo.

Idiomas de publicación: español, inglés, portugués y francés.

Título abreviado: Rev. Arquit.

Titulo corto: RevArq

\section{Políticas de sección}

La revista se estructura en tres secciones correspondientes a las líneas de investigación activas y aprobadas por la institución, y dos complementarias, que presentan dinámicas propias de la Facultad de Diseño y las publicaciones relacionadas con la disciplina.

CULTURA Y ESPACIO URBANO. En esta sección se publican los artículos que se refieren a fenómenos sociales en relación con el espacio urbano, atendiendo aspectos de la historia, el patrimonio cultural y físico, y la estructura formal de las ciudades y el territorio.

Proyecto ARQUitectónico y URBANO. En esta sección se presentan artículos sobre el concepto de proyecto, entendido como elemento que define y orienta las condiciones proyectuales que devienen en los hechos arquitectónicos o urbanos, y la forma como estos se convierten en un proceso de investigación y nuevo de conocimiento. También se presentan proyectos que sean resultados de investigación, los cuales se validan por medio de la ejecución y transformación en obra construida del proceso investigativo. También se contempla la publicación de investigaciones relacionadas con la pedagogía y didáctica de la arquitectura, el urbanismo y el diseño.

TECNOLOGÍA, MEDIOAMBIENTE Y SOSTENIBILIDAD. En esta sección se presentan artículos acerca de sistemas estructurales, materiales y procesos constructivos, medioambiente y gestión, relacionados con los entornos social-cultural, ecológico y económico.

DESDE LA FACULTAD. En esta sección se publican artículos generados en la Facultad de Diseño, relacionados con las actividades de docencia, extensión, formación en investigación o internacionalización, las cuales son reflejo de la dinámica y de las actividades realizadas por docentes, estudiantes y egresados; esta sección no puede superar el $20 \%$ del contenido.

TExTos. En esta sección se publican reseñas, traducciones y memorias de eventos relacionados con las publicaciones en Arquitectura y Urbanismo.

\section{A FRECUENCIA DE PUBLICACIÓN}

Desde 1999 y hasta el 2015, la Revista de Arquitectura publicó un volumen al año, a partir del 2016 se publicarán dos números por año en periodo anticipado, enero-junio y julio-diciembre, pero también maneja la publicación anticipada en línea de los artículos aceptados (versión Post-print del autor).

La Revista de Arquitectura se divulga mediante versiones digitales (PDF, HTML, XML) e impresas con un tiraje de 700 ejemplares, los tiempos de producción de estas versiones dependerán de los cronogramas establecidos por la editorial.

Los tiempos de recepción-revisión-aceptación pueden tardar entre seis y doce meses dependiendo del flujo editorial de cada sección y del proceso de revisión y edición adelantado.

Con el usuario y contraseña asignados, los autores pueden ingresar a la plataforma de gestión editorial y verificar el estado de revisión, edición o publicación del artículo.

\section{A CANJE}

La Revista de Arquitectura está interesada en establecer canje con publicaciones académicas, profesionales o científicas del área de Arquitectura y Urbanismo, como medio de reconocimiento y discusión de la producción científica en el campo de acción de la publicación.

\section{Mecanismo}

Para establecer canje por favor descargar, diligenciar y enviar el formato: RevArq FP20 Canjes

http://publicaciones.ucatolica.edu.co/revista/ arquitectura/RevArq_FP20_Canje_V2.doc

Universidad Católica de Colombia (2016, enero-junio). Revista de Arquitectura, 18(1), $1-144$.

ISSN: 1657-0308 E-ISSN: 2357-626X

Especificaciones:

Formato: $34 \times 24 \mathrm{~cm}$

Papel: Mate $115 \mathrm{~g}$

Tintas: Negro y policromía

\section{A CONTACTO}

DIRECCIÓN POSTAL:

Avenida Caracas No. 46-72. Universidad Católica de

Colombia. Bogotá D.C.(Colombia)

Código postal: 111311

Facultad de Diseño, Centro de Investigaciones (CIFAR). Sede El Claustro. Bloque "L", 4 piso, Diag. 46를. No. 15b-10. Editor, Arq. César Andrés Eligio Triana

Teléfonos: +57 (1) 3277300 - 3277333

Ext. $3109 ; 3112$ o 5146

Fax: +57 (1) 2858895

CORREO ELECTRÓNICO:

revistadearquitectura@ucatolica.edu.co cifar@ucatolica.edu.co

PÁGINA WEB:

www.ucatolica.edu.co vínculo Revistas científicas http://publicaciones.ucatolica.edu.co/revistas-cientificas http://editorial.ucatolica.edu.co/ojsucatolica/revistas_ucatolica/index.php/RevArq 
UNIVERSIDAD CATÓLICA DE COLOMBIA

PRESIDENTE

Édgar Gómez Betancourt

VICEPRESIDENTE - RECTOR

Francisco José Gómez Ortiz

VICERRECTOR JURÍDICO Y DEL MEDIO

UNIVERSITARIO

Edwin de Jesús Horta Vásquez

VICERRECTOR ADMINISTRATIVO

Édgar Gómez Ortiz

DECANO ACADÉMICO

Elvers Medellín Lozano

DIRECTORA DE INVESTIGACIONES

Elisa Urbina Sánchez

DIRECTORA EDITORIAL

Stella Valbuena García

\section{FACULTAD DE DISEÑO}

DECANO

Werner Gómez Benítez

DIRECTOR DE DOCENCIA

Jorge Gutiérrez Martínez

DIRECTOR DE EXTENSIÓN

Adriana Pedraza Pacheco

DIRECTOR DE INVESTIGACIÓN

Hernando Verdugo Reyes

DIRECTOR DE GESTIÓN DE CALIDAD

Augusto Forero La Rotta

COMITÉ ASESOR EXTERNO

FACUlTAD DE DisEÑo

Alberto Miani Uribe

Giovanni Ferroni Del Valle

Samuel Ricardo Vélez

Lorenzo Castro

FACULTAD DE DISEÑO

REVISTA DE ACCESO ABIERTO,

ARBITRADA E INDEXADA

Publindex Categoría B. Índice Bibliográfico Nacional

IBN. Colombia.

Redalyc. Red de Revistas Científicas de América Latina

y el Caribe, España y Portugal. Sistema de Información

Científica. México.

Proquest. ProQuest Research LibraryProQuest

Research Library ProQuest Research Library. Estados

Unidos

Ebsco. EBSCOhost Research Databases. Estados

Unidos.

Latindex. Sistema Regional de Información en Línea

para Revistas Científicas de América Latina, el Caribe,

España y Portugal (Directorio y catálogo). México.

Clase. Base de datos bibliográfica de revistas de cien-

cias sociales y humanidades. Universidad Autónoma

México.

Dialnet. Fundación Dialnet - Biblioteca de la Universi-

dad de La Rioja. España.

Actualidad Iberoamericana. (Índice de Revistas) Centro de Información Tecnológica (CIT). Chile.

Arla. Asociación de revistas latinoamericanas de arquitectura.

EDITORIAL

Av. Caracas No 46-72, piso 5

Teléfono: 3277300 Ext. 5145

editorial@ucatolica.edu.co

www.ucatolica.edu.co

http://publicaciones.ucatolica.edu.co/

IMPRESIÓN:

ESCALA Taller Litográfico

Calle 30 № 17-52 - (057 I) 2320482

Abril de 2016

\section{REVISTA DE ARQUITECTURA}

DIRECTOR

Werner Gómez Benítez

EDITOR

César Andrés Eligio Triana

EDITOR DE SECCIÓN

Carolina Rodríguez Ahumada

CONSEJO EDITORIAL

Werner Gómez Benítez

Jorge Gutiérrez Martínez

César Andrés Eligio Triana

Hernando Verdugo Reyes

\section{EQUIPO EDITORIAL}

COORDINADORA EDITORIAL

María Paula Godoy Casasbuenas mpgodoy@ucatolica.edu.co

DiseÑo Y MONTAJE

Juanita Isaza

juanaisaza@gmail.com

TRADUCTORES

INGLÉS

Massayel Cuéllar Hernández

massacuellar@gmail.com

CORRECTORA DE ESTILO

María José Díaz Granados M.

mariajose_dgm@yahoo.com.co

PÁGINA WEB

Centro de investigaciones (CIFAR)

DISTRIBUCIÓN Y CANJES

Claudia Álvarez Duquino

calvarez@ucatolica.edu.co
COMITÉ EDITORIAL Y CIENTÍFICO Cultura Y ESPACIO URBANO

Carlos Mario Yory, PhD

Universidad Católica de Colombia. Bogotá, Colombia

Sonia Berjman, $\mathrm{PhD}$

ICOMOS-IFLA, Buenos Aires, Argentina

Juan Carlos Pérgolis, MSc Universidad Piloto de Colombia. Bogotá, Colombia

Beatriz García Moreno, PhD

Universidad Nacional de Colombia. Bogotá, Colombia

Javier Peinado Pontón, Msc

Pontificia Universidad Javeriana. Bogotá, Colombia

Proyecto arquitectónico y URBano

Jean-Philippe Garric, PhD, HDR

Université Paris I Panthéon-Sorbonne. Paris, Francia

Debora Domingo Calabuig, $\mathrm{PhD}$

Universidad Politécnica de Valencia, España

Hugo Mondragón López, PhD

Pontificia Universidad Católica de Chile. Santiago, Chile

Germán Darío Correal Pachón, MSc Universidad Católica de Colombia. Bogotá, Colombia

Juan Pablo Duque Cañas, PhD

Universidad Nacional de Colombia. Bogotá, Colombia

Jorge Grané del Castillo, MSc Universidad de Costa Rica. San José, Costa Rica

\section{TECNOLOGÍA, MEDIOAMBIENTE Y SOSTENIBILIDAD}

Mariano Vázquez Espí, PhD.

Universidad Politéencica de Madrid, España.

Luis Carlos Herrera Sosa, PhD

Universidad Autónoma de Ciudad Juárez, México

Claudio Varini, PhD

Universidad Católica de Colombia. Bogotá, Colombia

Luis Gabriel Gómez Azpeitia, PhD Universidad de Colima. Colima, México 


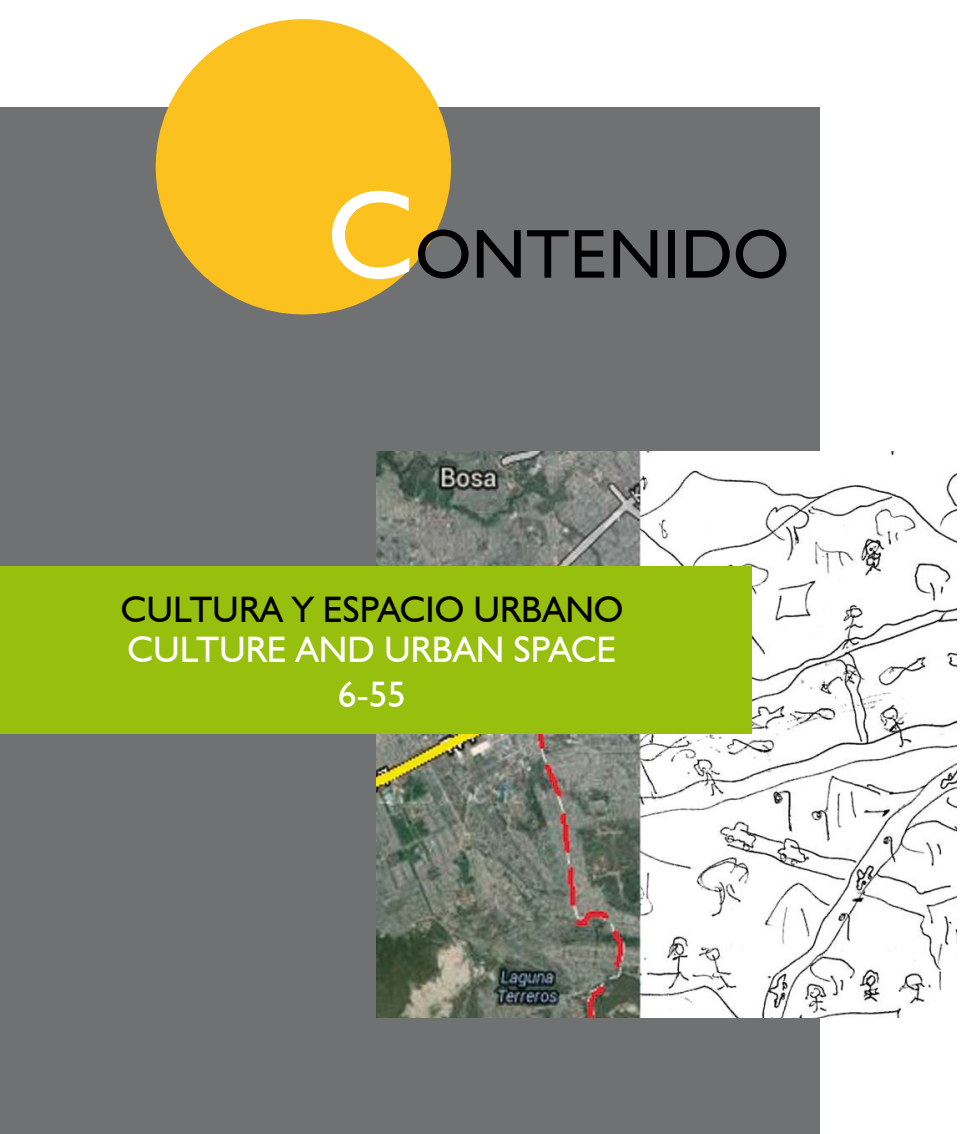

URBANISMO PARTICIPATIVO

CONSTRUCCIÓN SOCIAL DEL ESPACIO URBANO

MARY JOHANA HERNÁNDEZ ARAQUE

LA REPRESENTACIÓN SOCIAL DEL ESPACIO PÚBLICO PARA EL DISEÑO Y LA GESTIÓN DE TERRITORIOS SOSTENIBLES

UNA PROPUESTA TEÓRICO-PRÁCTICA Y METODOLÓGICA PARA UN URBANISMO PARTICIPATIVO

HeIDI NATALIE CONTRERAS-LOVICH

PROPUESTA DE UN SISTEMA DE INDICADORES PARA EVALUAR LA CALIDAD VISUAL DEL PAISAJE URBANO EN ASENTAMIENTOS INFORMALES

JOHANA ANDREA MESA CARRANZA, OSWALDO LÓPEZ BERNAL, ADRIANA PATRICIA LÓPEZ VALENCIA

\section{SEGREGACIÓN EN EL ESPACIO URBANO DE SOACHA}

¿TRANSMILENIO COMO HERRAMIENTA INTEGRADORA?

CARLOS AUGUSTO MORENO-LUNA

ARQUITETURA E INDUSTRIALIZAÇÃO DAS

CONSTRUÇÕES NA OBRA DE JOÃO FILGUEIRAS

LIMA - LELE

ELZA-LULI MIYASAKA, MARIELI LUKIANTCHUKI,

Michele C. B. Ferrari CaiXeta, Marcio-Minto Fabrício PÁg. 56

EL DISEÑO DE LA VIVIENDA DE INTERÉS SOCIAL

LA SATISFACCIÓN DE LAS NECESIDADES Y EXPECTATIVAS DEL USUARIO

ALEX LEANDRo PÉREZ-PÉREZ

\section{EXPLORACIONES MORFOLÓGICAS EN TEXTURAS} MODULARES

APROXIMACIONES DESDE EL OBIET TROUVÉ

AL DISEÑO PARAMÉTRICO

OMAR CAÑETE-ISLAS

TECNOLOGÍA, MEDIOAMBIENTE Y SOSTENIBILIDAD

TECHINOLOGY, ENVIRONMENT AND SUSTAINABILITY $76-125$
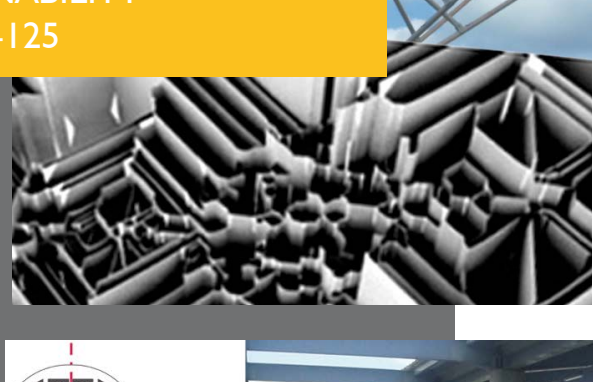

DESDE LA FACULTAD

FROM THE FACULTY 126-139

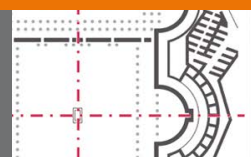

TEXTOS

TEXTS

I40-142
CONSTRUCCIÓN EXPERIMENTAL DE UN SISTEMA TRANSFORMABLE TENSADO PLEGABLE

CARLOS CÉSAR MORALES GUZMÁN

\section{LA SIMULACIÓN COMO HERRAMIENTA DE} DISEÑO Y EVALUACIÓN ARQUITECTÓNICA

PAUTAS RESUELTAS DESDE LA INGENIERÍA

JOHANNA TRUJILLO, ROLANDO ARTURO CUBILLOS-GONZÁLEZ

LAS RELACIONES ENTRE LA MOVILIDAD

Y EL ESPACIO PÚBLICO

TRANSMILENIO EN BOGOTÁ

Myriam STELLA Díaz-OSORIO, JuLIO CÉSAR MARRoQuíN

APRENDIZAJE, COMPOSICIÓN Y EMPLAZAMIENTO EN EL PROYECTO DE ARQUITECTURA [REVISIÓN DE LIBRO]

JUAN CARLOS PÉRGOLIS

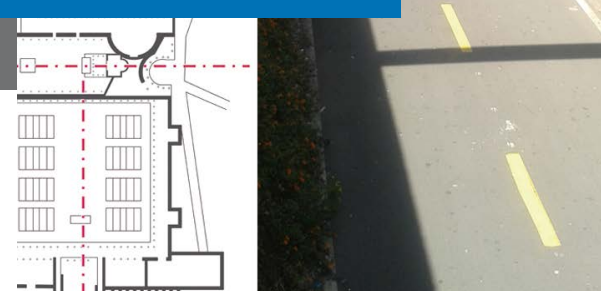




\title{
URBANISMO PARTICIPATIVO
}

\section{CONSTRUCCIÓN SOCIAL DEL ESPACIO URBANO}

\author{
Mary Johana Hernández Araque \\ Universidad La Gran Colombia. Bogotá (Colombia) \\ Grupo de investigación: Desarrollo Urbano Regional Sostenible (GDURS)
}

Hernández Araque, M. .. (2016). Urbanismo participati-

vo. Construcción social del

espacio urbano. Revista de

Arquitectura, $18(1), 6-17$. doi:

10.14718/RevArg.2016.18.1.2

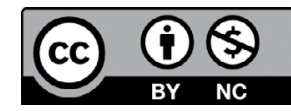

http://dx.doi.org/10.14718/RevArq.2016.18.1.2
Arquitecta, Universidad Santo Tomás, Tunja (Colombia).

Magíster en Gestión y Valoración Urbana, Universidad Politécnica de Cataluña, Barcelona (España).

Experiencia en proyectos arquitectónicos y urbanos.

Docente investigadora en la Facultad de Arquitectura de la Universidad La Gran Colombia, Bogotá (Colombia).

Docente honoraria en la Facultad de Arquitectura, Universidad de la República (Uruguay)

Participación en proyectos de investigación: Expediente urbano de centro histórico de la ciudad de Tunja (Boyacá), USTA Tunja, La Estación - recuperación de espacios públicos - Estudio de caso: Estación de La Sabana - Bogotá, Universidad de Los Andes.

maryhernandez_03@hotmail.com - johana.arquitecta@gmail.com

\section{RESUMEN}

Un común denominador de los problemas de las ciudades es la concepción de grandes proyectos urbanos que son ideados bajo políticas con intereses propios, que responden a un entorno físico que necesita transformarse, pero que casi siempre no reconoce las verdaderas necesidades del ciudadano. El propósito de este artículo es revisar las alternativas que desde hace unas décadas se han venido explorando como estrategia para ejecutar transformaciones urbanas que sean ágiles y que democraticen la participación del ciudadano, permitiendo ciudades incluyentes resultado de una construcción colectiva, que sean accesibles y que tengan una visión de sostenibilidad. Este trabajo aborda, a través de una revisión bibliográfica, tres etapas: en la primera, se revisa la normativa que hace referencia a la participación ciudadana en procesos de transformación urbana en Colombia; posteriormente, se indaga sobre el urbanismo participativo como nueva alternativa para la transformación de la ciudad y, al final, se hace un acercamiento al concepto de crowdsourcing como filosofía y herramienta para el urbanismo participativo. El documento permitirá conocer esta nueva forma de gestión urbana, la cual materializa de forma ágil e inmediata soluciones importantes para el ciudadano que requiere ser vinculado en la construcción del espacio urbano en el que se desenvuelve a diario.

PALABRAS CLAVE: ciudad planificada, crowdsourcing, derecho urbano, diseño urbano, gestión urbana, participación ciudadana.

\section{PARTICIPATORY PLANNING. SOCIAL CONSTRUCTION OF URBAN SPACE}

\section{ABSTRACT}

A common denominator of the problems of cities is the conception of large urban projects that are designed under self-interested policies. These respond to a physical environment that needs to be transformed, but almost always fails to recognize the real needs of citizens. The purpose of this article is to review the alternatives that, for some decades now, have been explored as a strategy to implement urban transformations that are agile and democratize citizen participation. This is how inclusive cities come to be the result of a collective construction, they are accessible and have a vision of sustainability. This paper addresses through a literature review, three stages: first, the legislation refers to citizen participation in urban transformation processes in Colombia is reviewed; then there is a research on participatory planning as a new alternative for the transformation of the city and, at the end, an approach to the concept of crowdsourcing as philosophy and tools for participatory planning is done. The document will reveal this new form of urban management, which materializes in flexible and immediate solutions important for citizens who need to be included in the construction of the urban space in which their lives unfold daily. KEYWORDS: Planned city, crowdsourcing, urban law, urban design, urban management, citizen participation. 


\section{INTRODUCCIÓN}

Este artículo es el resultado del marco teórico y conceptual de la investigación titulada "Formulación de herramientas para la gestión de un urbanismo participativo", adelantada por la autora, y se encuentra vinculada al grupo de investigación Desarrollo Urbano Regional Sostenible de la Facultad de Arquitectura de la Universidad la Gran Colombia.

La preocupación sobre la inactividad y falta de inclusión del ciudadano en la proyección y ejecución de los proyectos urbanos que transforman su entorno se convierte en la principal motivación para empezar a explorar, desde la teoría, aquellas nuevas alternativas de activismo ciudadano en la conformación de su espacio urbano.

Para comenzar, es preciso conocer el significado de ciudad, como objeto relacionado en este documento. La palabra "ciudad", según la Real Academia Española (RAE), hace referencia al espacio físico contenido dentro de un suelo urbano: "Conjunto de edificios y calles, regidos por un ayuntamiento, cuya población densa y numerosa se dedica por lo común a actividades no agrícolas" (figura 1). Si la RAE especifica que ciudad es el espacio urbano, entonces, ¿qué es lo urbano? Así pues, según la RAE, urbano es lo "Perteneciente o relativo a la ciudad". Ahora bien, teniendo claro el concepto de ciudad, reflexionar sobre los acontecimientos que ocurren en su cotidianidad y en la real vinculación del individuo que la habita, aquel que se ve directamente afectado por las trasformaciones de su entorno y por las decisiones de inter- vención y desarrollo del espacio físico (hace referencia al ciudadano que por procesos de transformación urbana se ve obligado a salir de su vivienda, o a aquel que en un radio próximo a sus actividades cotidianas no cuenta con espacios públicos apropiados para realizar actividades de recreación y ocio, o aquel que convive con espacios que se encuentran en estado de deterioro o contaminación, peligro, etc.; en conclusión, a cualquier habitante de la ciudad, en diferentes contextos, localizaciones o estratos que se vea afectado por cualquiera de estas circunstancias), se convierte en el punto de partida de este trabajo.

La ciudad como escenario de asentamientos humanos tiene una historia de casi diez mil años, donde el proceso de evolución y cambio de la misma están marcados por los acontecimientos políticos, económicos y sociales de cada época, acontecimientos que afectan no solo al ciudadano que la habita, sino, además, su dinámica y sus condiciones espaciales. Se ha planteado, al menos desde la teoría, que la transformación de los espacios urbanos debe hacerse de acuerdo con las necesidades que el ciudadano ha presentado según dichos acontecimientos. Es entonces donde se entra a analizar si, en nuestros días, el contexto de ciudad responde a las verdaderas necesidades de sus habitantes, si lo vincula en su procesos de desarrollo, y cuáles serían las nuevas alternativas para lograr que la ciudad sea el escenario que responda a los requerimientos de calidad de vida que todos necesitamos.

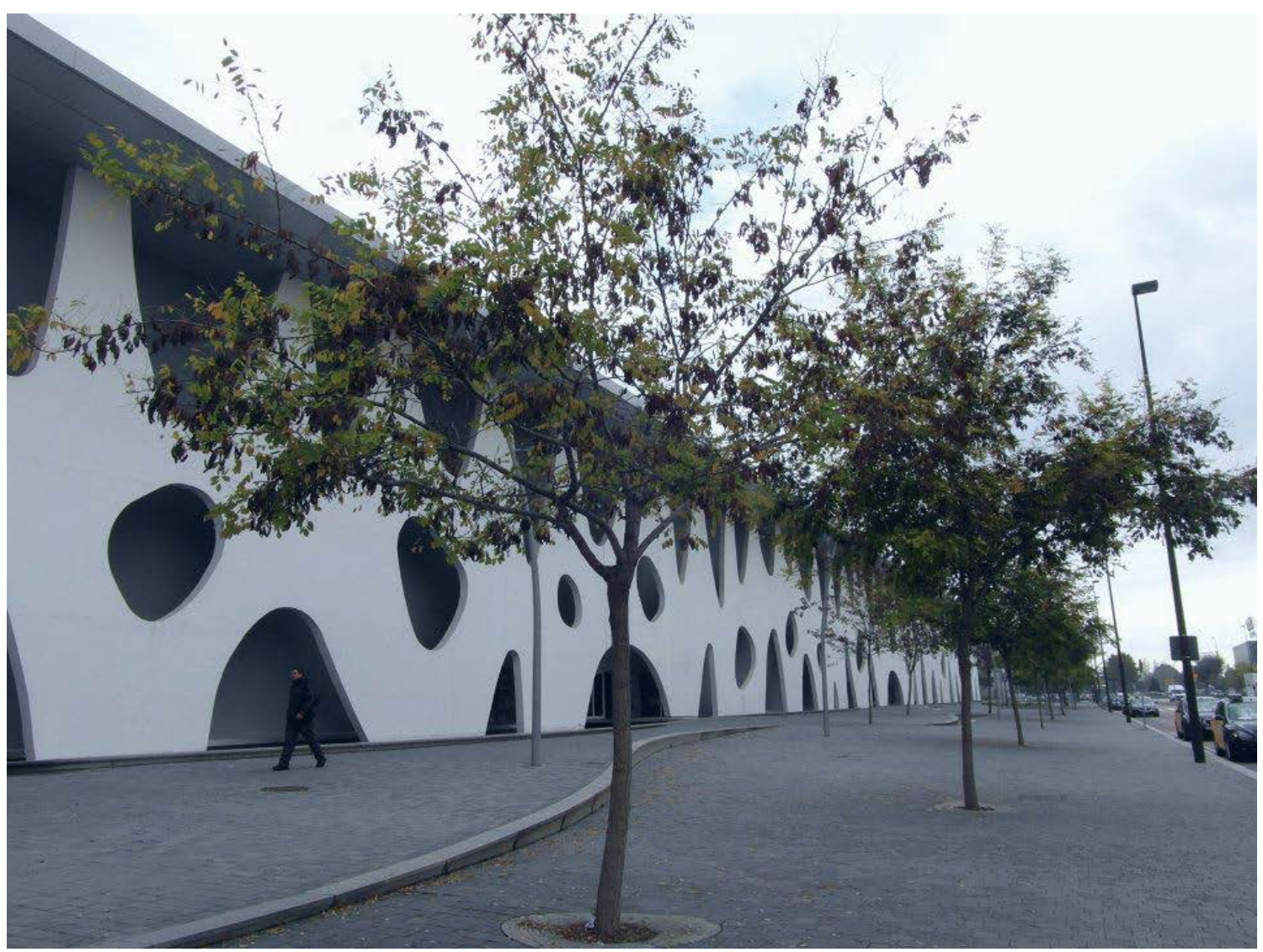

\&igura 1. Paisaje urbano.

Componentes de la ciudad - Inserción dentro del espacio natural - Relación directa con el ciudadano. Plaza de Europa, Hospitalet de Llobregat, provincia de Barcelona. Fuente: foto del autor. Noviembre de 2011. CC. BY 

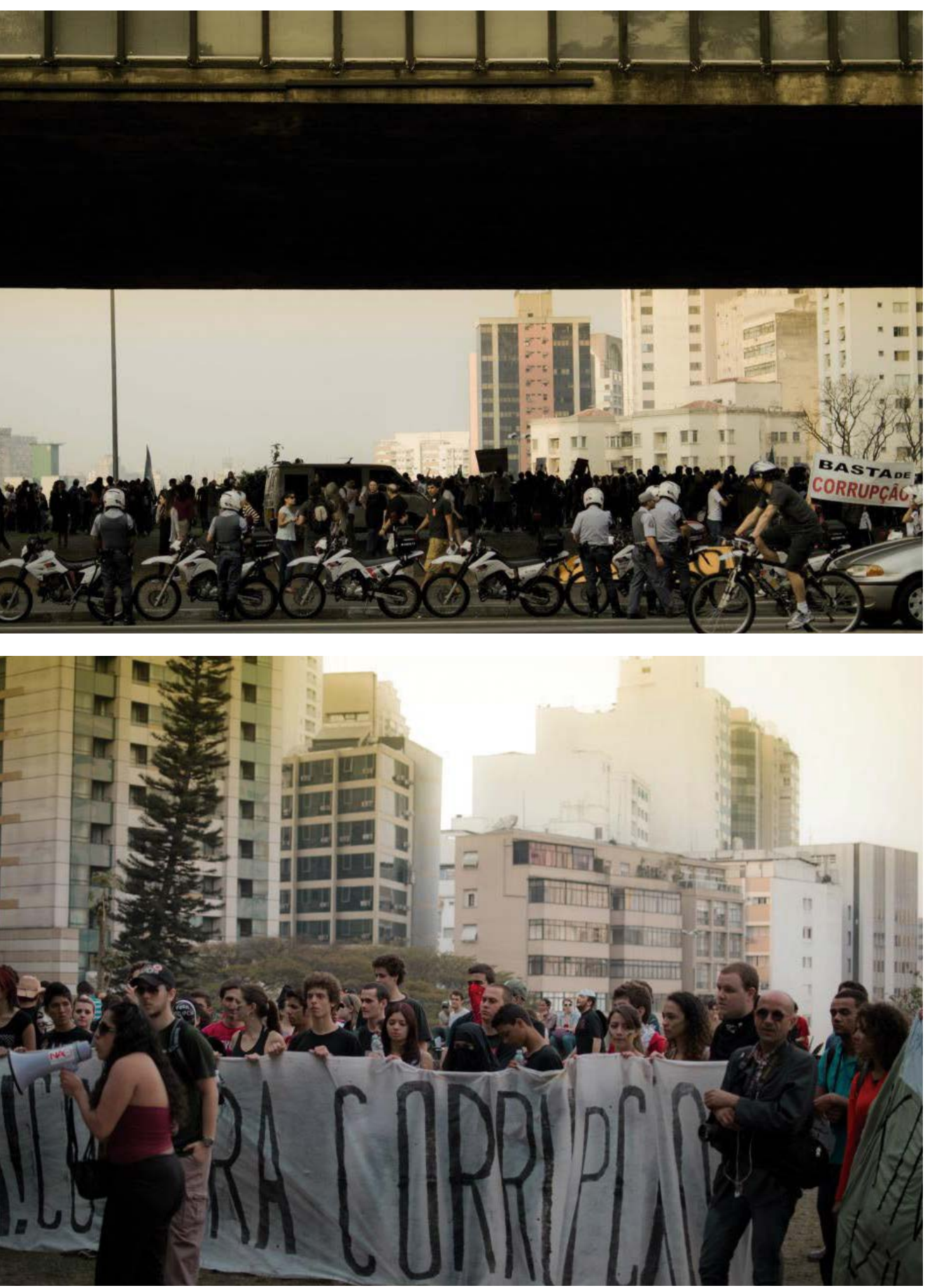

(A) Figuras 2 y 3 . Protesta (A) en São Paulo (Brasil), en el año 2013.

Manifestaciones de ciudadano en escenarios importantes de la ciudad pidiendo la inversión de recursos en proyectos urbanos y equipamientos que beneficien a la población en general Fuente: fotos del autor. CC. BY-ND Avenida Ibirapuera São Paulo (Brasil), junio de 2013
Es preciso aclarar que la reflexión sobre el tema de la participación ciudadana, el urbanismo participativo y el crowdsourcing a lo largo de este trabajo se hará de forma general, bajo la descripción de los conceptos nombrados. Sin embargo, para entender alguno de estos términos, se hará referencia a la normativa, los procesos y proyectos de ciudades o casos específicos.

Dentro de los procesos de gestión urbana, la participación ciudadana ha sido un tema que se ha intentado modernizar con nuevas metodologías y estrategias de enseñanza-aplicación que pretenden lograr una buena aportación de ideas y conceptos por parte de los ciudadanos, para así, por medio de estas, consolidar un colectivo/ ciudadano en la construcción, desarrollo y transformación de la ciudad; sin embargo, dichas metodologías generalmente se han quedado en la teoría, lo que se ha manifestado en los proyectos urbanos que se ejecutan en las ciudades, los cuales no responden a los intereses y anhelos del ciudadano y se realizan bajo los parámetros técnicos, económicos y políticos según la conveniencia de una minoría.

Teniendo en cuenta que el ciudadano es el directo afectado o beneficiado de los cambios territoriales que sufre su entorno, es ahí donde se ve la necesidad de materializar su real intervención en estos procesos de cambio y debe ser el principal activista en la gestión de su territorio.

En los últimos años se ha evidenciado un despertar del ciudadano carente de oportunidades e inconforme con su entorno y el manejo político-económico de los recursos de sus ciudades, el cual ha salido al espacio público a manifestar sus desacuerdos. Respecto a las disconformidades con el espacio físico de su ciudad, se tiene un antecedente desde los años cuarenta, cuando se empezaron a pronunciar a través de los conocidos movimientos vecinales, donde en un principio el ideal era la lucha por terrenos para la generación de viviendas, que se hacían cada día más necesarias debido al progresivo fenómeno de migraciones a la ciudad. Estas primeras manifestaciones colectivas en contra de los déficit de la gestión política sobre la vivienda y el hábitat en general, han tenido una reinterpretación en nuestros días, donde colectivos o asociaciones urbanas, conformadas por líderes, en su mayoría profesionales, y las comunidades locales de algún sector de la ciudad, buscan nuevas formas de hacer ciudad de abajo hacia arriba, rompiendo con la tradicional forma de gestión urbana de arriba (administración pública) hacia abajo (ciudadano).

Acercándonos a los tiempos actuales, es preciso dar una mirada a los acontecimientos de índole crítica y de protesta que han ocurrido en el transcurso de los últimos años en diferentes ciudades del mundo, en donde se ha dado un fenómeno de colectivismo ciudadano general en el que la lucha por intereses conjuntos se ha reflejado en la unión de la ciudadanía en búsqueda del cumplimiento a cabalidad de sus derechos; tal es el caso de Brasil (figuras 2 y 3$)^{1}$, cercano a nuestro contexto, en donde las protestas fueron organizadas principalmente como respuesta a la ejecución de grandes proyectos urbanos en donde no se contemplaron procesos de participación ciudadana.

Los brasileros piden mayor inversión estatal en educación y salud, y una reducción en el costo del transporte público. "Las demandas ciudadanas parecen refutar aquello que la dirigencia se ha dedicado a reivindicar una y otra vez" (La Nación, 2013, p. 2). Esta afirmación permite

1 Protestas en Brasil debido a los altos gastos del presupuesto nacional en la construcción de proyectos urbanos para la realización de la Copa Mundo 2014. 
establecer un cuestionamiento sobre la validez de los procesos de participación ciudadana que, para el caso de Colombia, están regulados por la legislación que rige los procesos de intervención y transformación urbana. Se diría que lo óptimo debería ser que la participación ciudadana no solo se quede en difundir un proyecto que de igual forma ya está definido y diseñado, y que en la mayoría de los casos no refleja los intereses de los habitantes, sino que el aporte de ideas, sugerencias o comentarios en este proceso de cumplimiento de los pasos dentro de la gestión territorial convierta al ciudadano en un agente que pueda apropiarse de las transformaciones, vinculándose a estas, teniendo en cuenta sus habilidades y contribuyendo al colectivo de ciudadanos que necesariamente deben estar inmersos en estos procesos de renovación, que favorecen la formación de ciudad.

Este escrito pretende definir, estudiar y analizar el concepto de urbanismo participativo ${ }^{2}$, como concepto fundamental para la formulación de herramientas de participación colectiva en la gestión de proyectos de transformación urbana. De la mano del concepto de urbanismo participativo, la filosofía del crowdsourcing como método de gestión de proyectos a través de la crowd participation (participación de multitudes que trabajan con un objetivo de beneficio común $)^{3}$ hace parte de la base conceptual de este escrito. Es importante desde ya, saber que el instrumento principal del modelo crowdsourcing son las herramientas web, aunque para el caso de este trabajo, más que el análisis de sus instrumentos, el aporte del concepto y la propuesta de trabajo como metodología para la gestión de proyectos, es el verdadero valor agregado para el mismo.

\section{Metodología}

Este trabajo busca mostrar un panorama sobre el concepto y los procesos de participación ciudadana desde un estudio normativo y teórico del mismo. Conociendo de manera general la teoría y las normas que refiere a este concepto, se hace una reflexión crítica, con una metodología cualitativa, sobre la validez de estos procesos de inclusión ciudadana en la conformación y ejecución de proyectos urbanos y, posteriormente, se hace una revisión de una tendencia de intervención urbana a través del activismo ciudadano, llamada urbanismo participativo.

2 Urbanismo emergente que establece pautas para el desarrollo de proyectos urbanos a través de la apropiación, participación, gestión, diseño y ejecución del mismo por parte de un colectivo de ciudadanos.

3 Metodología de trabajo colectivo para la gestión, promoción y ejecución de proyectos.
Lo anterior, a través de una revisión bibliográfica, donde los textos consultados son las normas que regularizan la participación ciudadana (en Colombia), y que permiten contextualizar al lector sobre las formas de participación que están aprobadas en el país, y los documentos que exponen el concepto de urbanismo participativo y crowdsourcing. Una vez compilada la información pertinente para el trabajo de investigación, en los documentos normativos se clasificaron aquellos apartados que hacen referencia puntualmente a la participación ciudadana (formas de actuación, alcance de la participación, escenarios de participación, entre otros). Estos se utilizaron solo a manera de información, sin llegar a profundizar en el ámbito político de la formulación de la norma. Los documentos que refieren al urbanismo participativo y al crowdsourcing permitieron conocer y entender la teoría de los conceptos $y$, al final, hacer una reflexión sobre la utilidad de estos como métodos de gestión urbana incluyente. La información de estos últimos se clasifico según definición, teoría, procedencia y formas de aplicación.

\section{RESULTADOS}

\section{LA PARTICIPACIÓN CIUDADANA DESDE LA Constitución Política de COLOMBIA. AsPeCtos NORMATIVOS}

Sabiendo que el significado del término ciudadano hace referencia a aquel individuo ocupante de un área territorial (urbano-rural) que posee derechos y deberes, en este apartado se hará la revisión de aquellos derechos que por norma, desde la reforma constitucional de 1991, se le asignan al ciudadano. Para este caso, se hará relevancia en aquellos que tienen que ver con su intervención, representación y participación en términos de ordenamiento, transformación, renovación e intervención del territorio en el que habita. Según lo anterior, Carrión afirma que:

La Constitución Política de 1991 incorporó gran parte de los procesos de descentralización promovidos durante la década de los años 80 del siglo pasado, dando inicio a discusiones sobre un nuevo modelo de Estado y sobre la necesidad de desarrollar normas e instrumentos para la planeación y el ordenamiento territorial con aplicación municipal (2011, p. 1).

Al respecto, es preciso citar el artículo 311 de la Constitución:

Sobre la base de estas reformas políticas y sociales, se asumió al municipio como la entidad fundamental de la división político-administrativa del Estado colombiano, correspondiéndole la prestación de los servicios públicos que determine la ley, la construcción de obras que demande el progreso local, la ordenación del desarrollo de su territorio, y la promoción de la participación comunitaria, entre otras funciones y competencias (Constitución Política de 1991). 
(1) Tabla 1. Resumen de los artículos de la Constitución Política de Colombia de 1991, que hacen referencia a la participación ciudadana Fuente: elaboración propia.
Así pues, son varios los artículos establecidos en la Carta Magna que hacen referencia a esos derechos que le permiten al ciudadano exigir que se tenga en cuenta su opinión y voto frente a diferentes aspectos de cambio e intervención donde se vea directamente afectado. Tomando como preámbulo la revisión de la Constitución de 1991, que en su artículo 1 dice: "Colombia es un Estado social de derecho, organizado en forma de República unitaria, descentralizada, con autonomía de sus entidades territoriales, democrática, participativa y pluralista, fundada en el respeto de la dignidad humana, en el trabajo y la solidaridad de las personas que la integran y en la prevalencia del interés general", es preciso resaltar la intención general y primordial de la norma nacional al hacer énfasis en que es un Estado social de derecho, lo que implica tener claro que la política nacional debe tener como fundamento el velar por los derechos que se le asignan a los ciudadanos; además, que los calificativos descentralizada, democrática y participativa sientan las bases que le conceden al ciudadano el derecho fundamental a la participación en todos los aspectos (políticos, religiosos, culturales, etc,) y, además, le reconoce el derecho a tener voz y voto en las decisiones que afecten la sociedad y el territorio; la prevalencia del interés general sería la frase con mayor significado en la composición de este primer artículo, ya que además de ratificar la denominación de Estado social de derecho, permite dar mayor relevancia a los actos de participación ciudadana como metodología para la exposición de ideas y necesidades por parte del ciudadano, generando un debate colectivo que debe tener como resultado la proyección de estrategias e intervenciones que cumplan con este objetivo.

La tabla 1 muestra los principales artículos de la Constitución Política de Colombia de 1991, que hacen alusión de forma general a la participación ciudadana.

En un documento de reflexión sobre el tema de la participación ciudadana en relación con la Constitución, se presenta una revisión de la norma en términos de:

La preocupación central de una democracia auténtica consiste en garantizar que todos los miembros de la sociedad tengan una posibilidad real e igual de participar en las decisiones colectivas. Así, cuando nuestra Constitución establece desde su primer artículo que Colombia es

\section{Participación ciudadana - Constitución Política de Colombia, 1991}

Artículo 2 Son fines esenciales del Estado: [...] facilitar la participación de todos en las decisiones que los afectan y en la vida económica, política, administrativa y cultural de la Nación.

Artículo 23 Toda persona tiene derecho a presentar peticiones respetuosas a las autoridades por motivos de interés general o particular y a obtener pronta resolución.

Artículo 38 Se garantiza el derecho de libre asociación para el desarrollo de las distintas actividades que las personas realizan en sociedad.

Todo ciudadano tiene derecho a participar en la conformación, ejercicio y control del poder político. Para hacer efectivo este derecho puede:

1. Elegir y ser elegido.

Artículo $40 \quad$ 2. Tomar parte en elecciones, plebiscitos, referendos, consultas populares y otras formas de participación democrática.

3. Constituir partidos, movimientos y agrupaciones políticas sin limitación alguna; formar parte de ellos libremente y difundir sus ideas y programas.

4. Tener iniciativa en las corporaciones públicas.

Artículo 270

La ley organizará las formas y los sistemas de participación ciudadana que permitan vigilar la gestión pública que se cumpla en los diversos niveles administrativos y sus resultados.

La correspondiente ley orgánica reglamentará todo lo relacionado con los procedimientos de elaboración,

Artículo 342 aprobación y ejecución de los planes de desarrollo y dispondrá los mecanismos apropiados para su armonización y para la sujeción a ellos de los presupuestos oficiales.

La ley determinará los deberes y derechos de los usuarios, el régimen de su protección y sus formas de participación en la gestión y fiscalización de las empresas estatales que presten el servicio. Igualmente definirá la participación de los municipios o de sus representantes, en las entidades y empresas que les presten servicios públicos domiciliarios. 
una República democrática y participativa, está asumido el reto y el compromiso de promover la participación ciudadana en todos los espacios de la vida social (Subgerencia Cultural del Banco de la República, 2015).

Existen dos canales fundamentales a través de los cuales se pone en práctica la participación ciudadana; el primero es el de la representación y el segundo el de la participación directa. El primer camino ha permitido que los ciudadanos escojan sus líderes políticos a los cuales, en principio, les corresponde ser promotores y gestores de los proyectos urgentes para la ciudad, y aquellos que la proyectan a futuro. Sin embargo, y sin entrar en una discusión política, algunos de estos representantes, para el caso de Bogotá, no han resultado tan efectivos para la ciudad y sus habitantes debido a la negligencia en la gestión y a la obsolescencia en la proyección de transformaciones urgentes en la ciudad. Por esto, tomar como opción la participación directa, viene siendo una oportunidad para explorar nuevas estrategias de gestión que den resultados tangibles e inmediatos.

A través de toda una serie de herramientas consagradas en la Constitución y reguladas en las leyes nacionales, los Colombianos podemos entablar una relación directa con las autoridades públicas, dar a conocer nuestras propuestas, presionar para que sean adoptadas, opinar sobre asuntos públicos, exigir el cumplimiento de las normas, vigilar la conducta de los dirigentes, tomar decisiones que nos afectan a todos o sancionar a los gobernantes que actúan de forma equivocada, entre otras formas de participación. Ahora bien, todo lo anterior de nada serviría si los ciudadanos no pudieran presentar sus puntos de vista frente a los espacios en los que se toman las decisiones políticas que afectan a la colectividad. Esto implica que todas las oficinas, corporaciones y agencias del Estado tienen que estar abiertas a la participación de los ciudadanos, bien sea para que estos las controlen o bien para que estos se informen de lo que ellas hacen, presenten sus propuestas y participen en las decisiones que estas adoptan (Sentencia C-169 de 2001).

Se sabe que la actual Constitución se originó en un momento en el que el país veía la necesidad de dar una apertura a espacios democráticos que incluyeran al ciudadano en los procesos de transformación del territorio, para hablar puntualmente del tema que concierne a este trabajo.

Carlos Echeverri hace una reflexión acerca de la participación ciudadana desde una perspectiva constitucional y normativa estatutaria, donde trae a colación el siguiente apartado de la sentencia C-179 de 2002:

Enfatiza la Corte que en un modelo de democracia participativa: no todas las decisiones se dejan a los representantes elegidos democráticamente, sino que algunas pueden ser adoptadas, complementadas o modificadas directamente por el pueblo o con su intervención, a través de figuras como el plebiscito, el referendo, la consulta popular, la iniciativa popular y el cabildo abierto (2010, p. 65).
Por último, es necesario anotar que aunque la participación hace parte de la función pública, lo privado también debe tomar la responsabilidad de intervenir la ciudad teniendo en cuenta las necesidades del ciudadano, respondiendo con sus transformaciones a dichas falencias a través de procesos de participación como escenarios y espacios para la expresión de ideales, iniciativas y propuestas.

\section{PARTICIPACIÓN CIUDADANA EN LA LEY 388 DE 1997 (LEY DE ORDENAMIENTO TERRITORIAL)}

La Ley 388 de 1997, ley nacional que refiere al ordenamiento territorial, tiene dentro de sus objetivos principales, ser el documento normativo por medio del cual se establecen parámetros generales para el ordenamiento territorial de los municipios, el adecuado uso del suelo, su utilización de acuerdo con los objetivos principales de la propiedad y su función social, y armonizar la entidades territoriales con las autoridades ambientales y la Administración nacional para lograr una óptima planificación, entre otros.

En términos de la participación ciudadana dicha ley, desde su artículo $4^{\circ}$, contempla y expone la importancia de la participación del ciudadano en los procesos de formulación, diseño y ejecución de los proyectos que transforman y desarrollan la ciudad.

Es así como el artículo $4^{\circ}$ de la Ley 388, dispone el papel central que ocupa la participación democrática en las diferentes actividades que conforman las acciones urbanísticas, mediante las cuales, las administraciones municipales, distritales y metropolitanas deberán fomentar la concertación entre los intereses sociales, económicos y urbanísticos. Dicha concertación tendrá por objeto asegurar la eficacia de las políticas públicas respecto de las necesidades y aspiraciones de los diversos sectores de la vida económica y social relacionados con el ordenamiento del territorio municipal (Corredor, 2012, p. 16).

La evidencia documental sobre la participación ciudadana legislada y reglamentada en Colombia, es clara. Sin embargo, y volviendo a uno-de los objetivos de este trabajo, donde la reflexión se dirige a la veracidad de la participación ciudadana en los procesos de transformación de la ciudad, las evidencias físicas en los proyectos urbanos muestran otros resultados. Lo anterior debido a que, en muchas ciudades, la participación ciudadana ha tomado un rumbo meramente informativo, donde se le avisa al ciudadano de los proyectos planteados, una vez ya están diseñados y estructurados, tomando este proceso como un simple cumplimiento a lo exigido dentro de los pasos para la gestión. La propuesta final de todo el trabajo de investigación en el 
que está incluido este primer documento teórico, le apunta a la insistencia de que estos procesos de participación deben empezar a tener un rumbo nuevo, que contemple y diseñe nuevas herramientas y metodologías que hagan visible el proceso de participación ciudadana más allá de la normativa, donde el ciudadano sea proponente, diseñador, participe en la ejecución y sea el mayor beneficiado con las transformaciones de la ciudad y los cambios reales que pueden traer consigo.

Para culminar esta revisión legal sobre el aspecto de la participación ciudadana, es preciso traer a colación el artículo 2 de la Ley 507 de 1999, la cual modificó algunos aspectos de la Ley 388 de 1997, la cual dispone que: "los Concejos Municipales o Distritales, [...] celebrarán obligatoriamente un Cabildo Abierto previo para el estudio y análisis de los Planes de Ordenamiento Territorial sin perjuicio de los demás instrumentos de participación contemplados en la ley", dando una vez más cabida al ciudadano en los procesos de formulación de los instrumentos de planificación territorial.

Este trabajo, además, sugiere que los proyectos urbanos ejecutados en la gran mayoría por las entidades públicas, inducen a imaginar que la responsabilidad de que la participación ciudadana sea un proceso veraz y efectivo recae únicamente en el sector público, pero no es así. Hay que entender, dentro de la reflexión, que la participación ciudadana también es una labor del sector privado y de cualquier otro que se plantee proyectos de cambio para la ciudad. Es aquí donde el ciudadano, además, debe hacer su parte y convertirse en un activista importante para su ciudad, en un agente de cambio, dejando atrás su pasividad típica que, por lo general, aguarda únicamente por las soluciones que el gobierno pueda dar. Por esto, para encontrar esta acción y reacción en el ciudadano, se plantean nuevas alternativas de intervención urbana a partir del empoderamiento del habitante de la ciudad.

Finalmente, el Decreto Distrital 448 de 2007, el cual "establece la obligatoriedad de que los sectores del gobierno Distrital diseñen y desarrollen estrategias de investigación, formación, información y movilización como parte del proceso de participación ciudadana", concluye lo que se ha escrito hasta el momento en este trabajo, sobre la obligación de una apropiada participación ciudadana a manera de vinculación directa, y no de un único proceso informativo.

A continuación se aborda el significado y la interpretación de un concepto en auge en el urbanismo, que es la herramienta por explorar en este trabajo, como estrategia para lograr una participación ciudadana enfocada en el activismo, la apropiación y el empoderamiento del ciu- dadano en los temas que refieren a la ciudad y su planificación territorial, este concepto es el urbanismo participativo ${ }^{4}$.

\section{EL URBANISMO NECESITA ACTIVISMO CIUDADANO}

Para comenzar, veamos una definición básica del concepto de gestión urbana:

\begin{abstract}
...conjunto de iniciativas, instrumentos y mecanismos para la normalización de la ocupación y el uso del suelo urbano y el suelo rural (gestión territorial), articuladas por fuerzas políticas e iniciativas de la sociedad local (gestión política), y que tiene como finalidad la generación de procesos de planificación urbanística que deberán asegurar la preservación del interés público frente al privado (gestión urbanística) (Gaete, 2005).
\end{abstract}

Para el caso de Colombia, los procedimientos e instrumentos de gestión y actuación urbanística están definidos en la Ley 388 de 1997.

Esta definición conlleva entender la transversalidad que debe tener un proceso de gestión urbana, donde los componentes deben tener un carácter político, económico, académico, social, territorial y profesional en diferentes disciplinas, para lograr resultados óptimos. Esta afirmación era el común denominador de muchos estudios urbanos que hasta hace poco mezclaban las diferentes estructuras anteriormente nombradas, como metodología para hacer y ejecutar proyectos.

Rafael López Rangel, en su escrito Las teorías urbanas, un tema transdisciplinario, no neutral, hace una aproximación a ciertos parámetros de la gestión urbana en Latinoamérica, a partir de algunas propuestas que tienen un carácter epistemológico y de la sociología del conocimiento, en la que a pesar de que ve estos procesos como un sistema complejo de gestión y participación, expone unos principios que hablan de las diferentes vinculaciones de actores que entran en estos procesos, los cuales son: Principio dialógico (figura 4), "une dos principios o nociones que se excluyen mutuamente, pero son indisociables en una misma realidad. [...] Ejemplos: ciudad-sociedad/ naturaleza, globalización/autonomía soberana, etc.". Por su parte, el Principio hologramático,

...se refiere a la relación del todo con las partes. Emana de la certeza de que no solo la parte se encuentra en el todo, sino que también el todo está en las partes, sin que estas pierdan su singularidad. Asimismo, se da la posibilidad de que una modificación en una de las partes puede llegar a regenerar el todo. Los ejemplos: las interrelaciones hologramáticas entre barrios, colonias, sectores urbanos y la ciudad en su conjunto. [...] En una metrópoli: negociado, diputado, ancestral, colectivizado" (2012, p. 8).

4 También conocido como urbanismo emergente o urbanismo táctico (Steffens, 2014). A lo largo de este trabajo se hará referencia al mismo con cualquiera de estas tres denominaciones. 


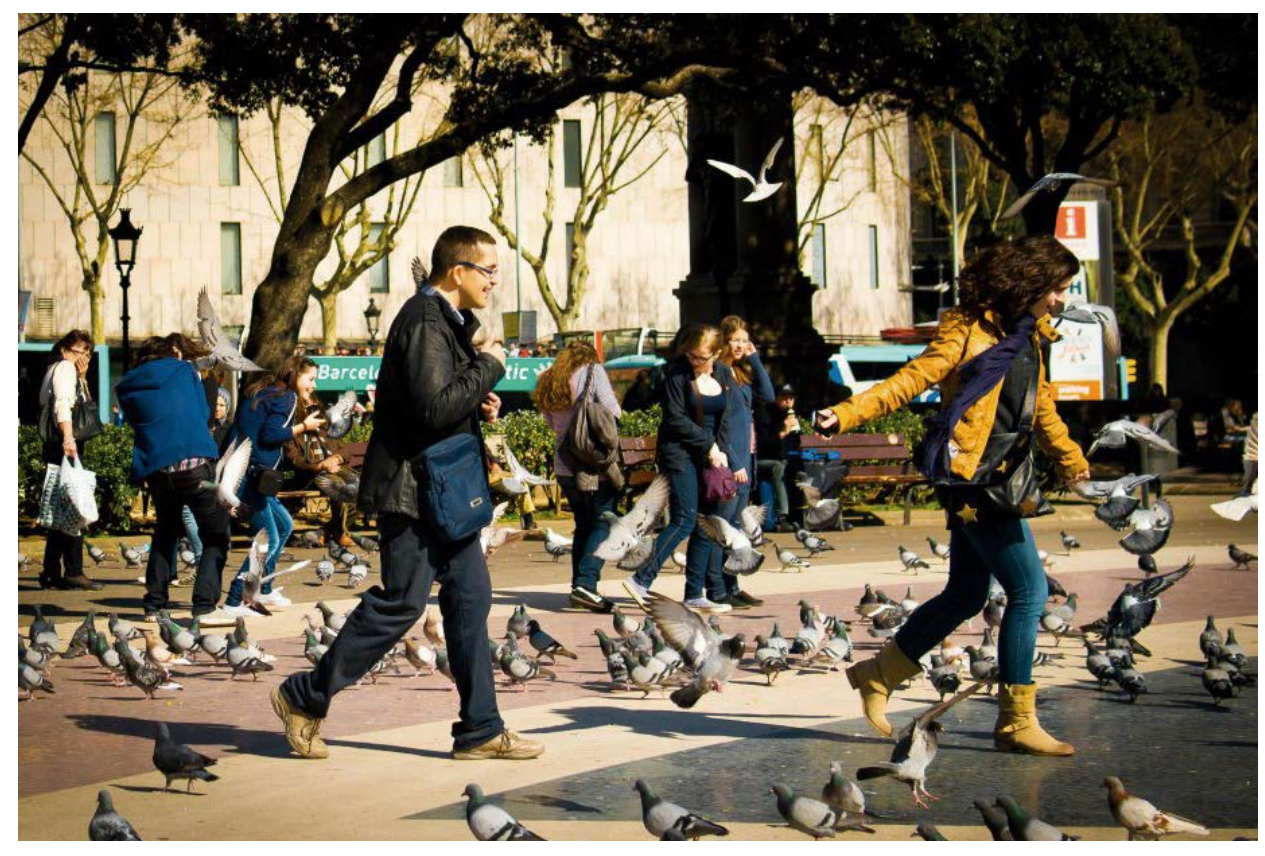

\& Figura 4. Representación de los actores principales de la ciudad. Ciudadano, medio ambiente, territorio. Espacio colectivo y participativo. Plaza Cataluña, Barcelona (España)
Por último, el principio de recursividad viene siendo el más significativo para este trabajo, sin dejar a un lado la relevancia de los otros dos, dado que en este se afirma que:

Parte del reconocimiento de que los efectos o productos y las causas son ellos mismos productores y causantes de lo que los produce, de esto se desprende que los individuos y los grupos sociales producen la ciudad y la sociedad a través de sus interacciones, pero al mismo tiempo, la sociedad y "la ciudad" producen a los individuos y grupos sociales, aportándoles lenguaje y cultura (López Rangel, 2012, p. 8) (Ver proyectos ejemplo en las figuras 5 y 6 )

Al referirse a otros autores que han trabajado la gestión social del territorio como sustancia referencial para este escrito, y que dejan ver a través de sus teorías la importancia que deben tener los procesos de participación y activación ciudadana para resolver la carencia de gestión inmediata a problemáticas del urbanismo por parte del sector gubernamental, vemos que:

\begin{abstract}
El territorio y los asentamientos humanos tampoco están quietos, porque no son espacios físicos inertes, sino que cambian con la acción de sus ocupantes o gobernantes y estos los alteran con sus prácticas para adaptarlos al medio y a las necesidades del grupo, reconfigurándolos una y otra vez en procesos continuos de transformación del territorio. Pues precisamente reconocer los procesos sociales por los que se producen las transformaciones culturales del espacio, es decir, los procesos morfogenéticos que determinan los cambios del espacio construido en cada cultura, época y territorio es identificar los modos universales posibles y sus combinaciones de todas las formas de gestión social territorial (García y García, 2005, p. 4).
\end{abstract}

Es precisamente este el fundamento del urbanismo participativo, la gestión del territorio a través del activismo social. Así pues, después de

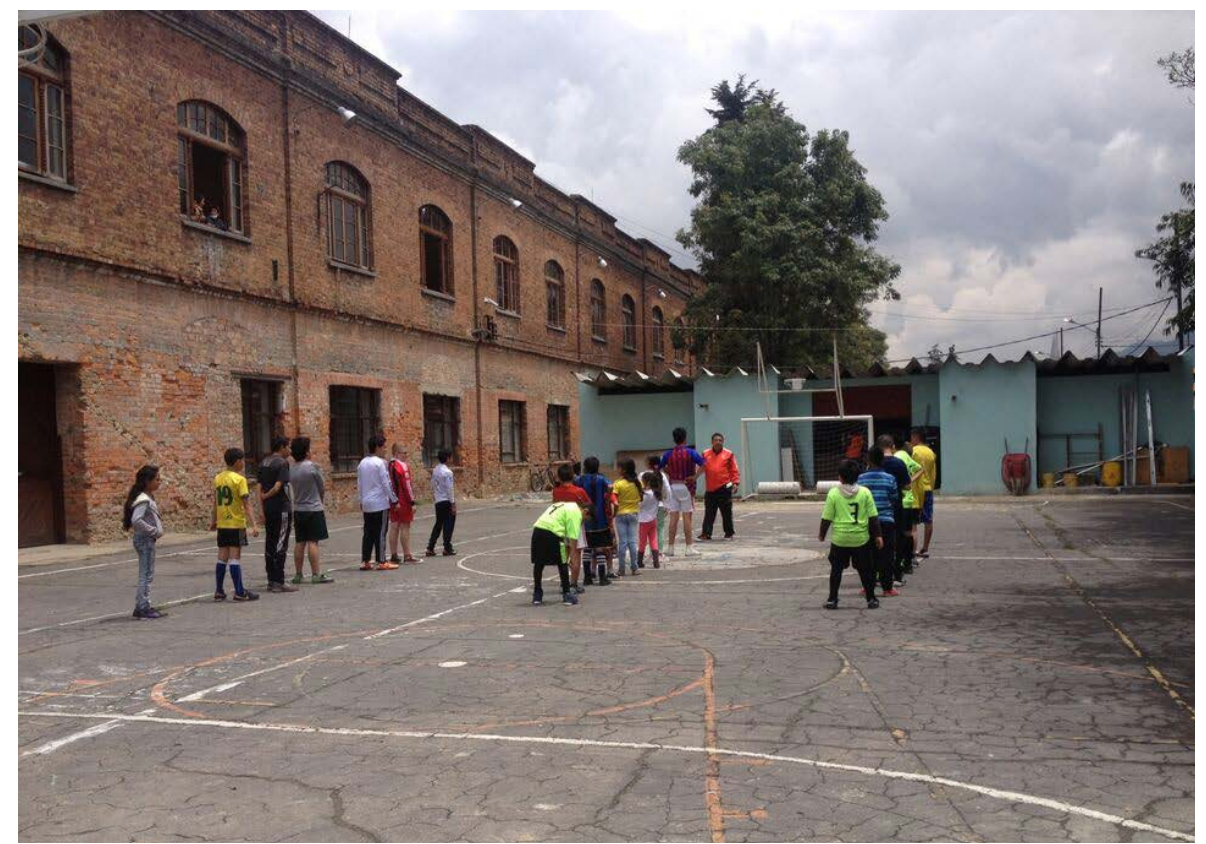

(A) Figura 5. Proyecto de construcción social de espacio público. Localidad de Los Mártires, Bogotá (Colombia). Colectivo Amigos de la Estación. Estación de la Sabana Fuente: foto del autor, agosto de 2013. CC. BY.

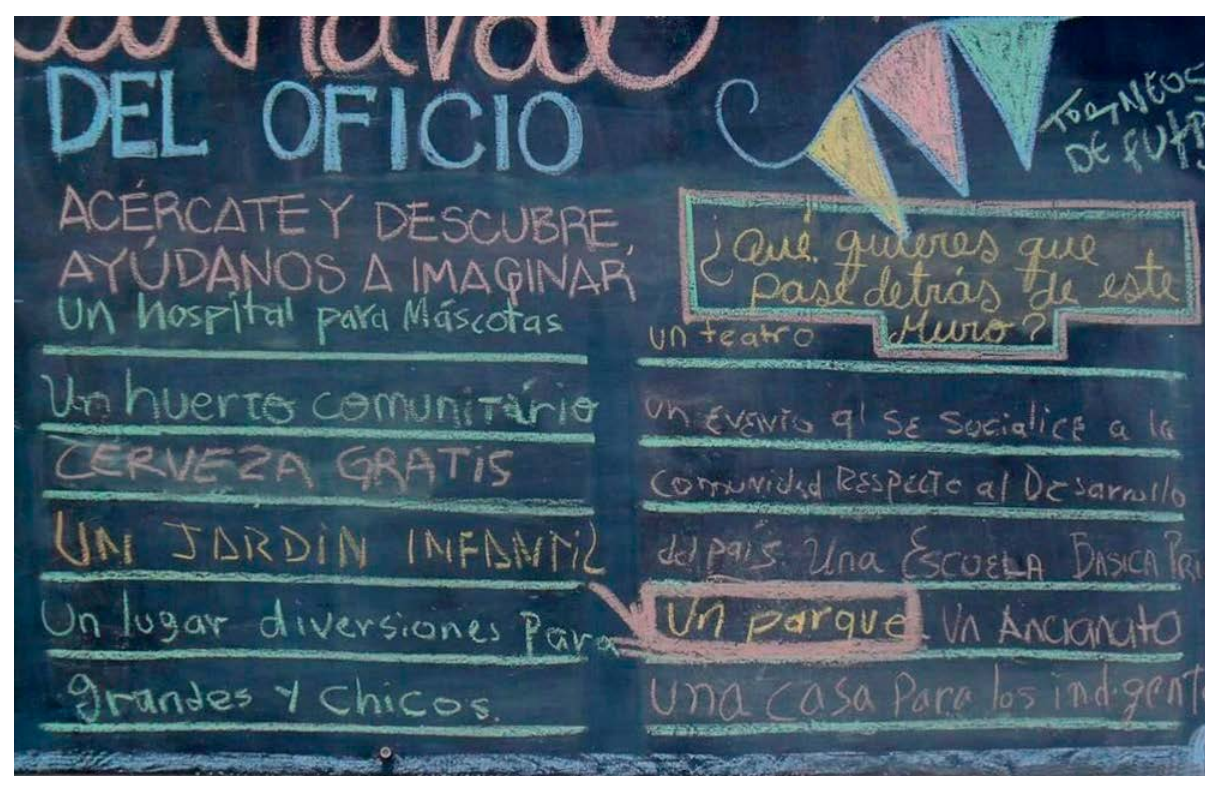

(A) Figura 6. Actividad de diseño participativo. Lluvia de ideas aportadas por la comunidad de la localidad de Los Mártires para la intervención de un espacio público. Calle 13, centro de Bogotá

Fuente: foto del autor, octubre de 2013. CC. BY. 
estas definiciones preliminares sobre las formas de gestión del urbanismo social, es preciso definir de forma puntual, según autores reconocidos en el tema, lo que es el urbanismo participativo: "se basa en la participación ciudadana como punto importante en la 'construcción' de la ciudad. [...] Podríamos resumirlo diciendo que el urbanismo emergente realiza una cartografía del papel de los ciudadanos y habitantes como productores de ciudad bottom-up frente a la visión top-down de la planificación urbanística tradicional" (Reyes, 2011, p. 7).

Otros autores se refieren al término como urbanismo táctico:

Uno de los desafíos de hacer ciudad en la era urbana es el involucramiento de los ciudadanos en la toma de decisiones. Sin duda, las negociaciones en la planificación urbana son procesos difíciles, pero afortunadamente existen acciones a corto plazo que logran gatillar cambios a largo plazo y que ponen a la ciudadanía en el centro de la cuestión. Esas son tácticas posibles de ser implementadas aquí y ahora, que ayuden a enriquecer el capital social de las comunidades y a comunicar la visión de un proyecto de forma efectiva (Vergara Petrescu, 2013, p. 13).

Di Sierna afirma que el urbanismo emergente es el "conjunto de acciones o micro-acciones que los propios ciudadanos ponen en marcha de forma espontánea y basados en la autoorganización, con el objetivo de modificar o mejorar su hábitat. Por consiguiente la ciudad se vuelve a entender como un espacio de producción social" (2012, p. 2).

Hace aproximadamente una década se viene trabajando y vinculando la metodología de inclusión del ciudadano a través del urbanismo participativo en países del continente europeo - los pioneros-, y en algunos países latinoamericanos, a manera de teoría e investigación en estudios urbanos ${ }^{5}$.

Así pues, de un tiempo hacia aquí se está reivin-
dicando la participación ciudadana en la genera-
ción de espacios urbanos y ya se ha empezado
a dar respuestas incipientes, ya sea proporcio-
nando información sobre los procesos y dejando
opinar a la ciudadanía (normalmente sobre
temas banales), o bien sea diseñando sistemas de
participación abiertos (Freire, 2009, p. 24).

El urbanismo participativo está incursionando como una metodología de participación mediante la cual se busca generar en el ciudadano una apropiación sobre el espacio urbano en el cual se puede encontrar una oportunidad para satisfacer sus necesidades. El urbanismo participativo está visto como un "urbanismo de menor escala y mayor agilidad que implica la

5 Propone intervenir la ciudad a través de las iniciativas del ciudadano, el cual adquiere un rol de prosumidor, es decir, de productor y a la vez consumidor de espacios urbanos. participación ciudadana y que se conoce como urbanismo emergente, de guerrilla o urbanismo táctico" (Reyes, 2011, p. 3).

Este concepto se explora con el objetivo de reflexionar sobre estas nuevas metodologías, donde se persigue mostrar y comprender cómo la sociedad y sus diversas formas de organización intervienen en los procesos urbanos, y cómo el espacio urbano, a través de pequeñas acciones, va construyendo ciudad. Una forma de hacer ciudad que rompe el esquema tradicional de arriba hacia abajo dándole un giro de 180 grados.

El siguiente apartado conceptualiza el término crowdsourcing como un complemento filosófico del urbanismo participativo y como una herramienta para la implementación del mismo.

\section{CROWDSOURCING: MULTITUD EXTERNALIZANDO INICIATIVAS}

El crowdsourcing entró en auge hace aproximadamente una década, acuñado por Jeff Howe (2006), quien lo expuso en un artículo de la revista Wired, titulado "El ascenso del crowdsourcing"6.

En términos generales, la teoría del crowdsourcing define estrategias innovadoras de participación y trabajo colectivo para la ejecución de proyectos, solución de problemáticas y creación de iniciativas de gran impacto para un grupo de personas.

Es preciso traer a colación este término por dos razones: la primera, porque la filosofía del crowdsourcing como metodología de trabajo colectivo, de gestión de proyectos a través del empoderamiento de un grupo de personas y del activismo de las mismas en la ejecución de los planes, tiene una relación directa con el fundamento y modelo de ejecución de los proyectos que se hacen bajo el concepto del urbanismo participativo. En segundo lugar, el crowdsourcing tiene como instrumento de trabajo las herramientas web, utilizadas para difundir información, divulgación de iniciativas, plataformas de comunicación entre los miembros del grupo gestor y ejecutor y, en general, como forma de comunicación; así pues, se puede pensar que en estos momentos, donde los avances tecnológicos (sistemas, redes, grupos sociales online) hacen parte de la cotidianidad del ciudadano ${ }^{7}$, estas herramientas web podrían considerarse en los procesos de transformación urbana colectiva como medio entre la información y el ciudadano.

6 The rise of crowdsourcing.

7 En Colombia, según estudios de Ipson MediaCT (The media, Content and Technology Research Specialists), el $80 \%$ de los habitantes en ciudades mayores a 200. 000 habitantes, usan Internet (dentro y fuera de su casa). 
Actualmente existen muchos colectivos urbanos alrededor del mundo. En estos, los temas de trabajo giran alrededor de la ciudad, las transformaciones de la misma a través de acciones urbanas a menor escala principalmente, y la gestión territorial; en las últimas décadas, estos han tenido un interés colectivo en la innovación de las estrategias para la gestión del territorio que tengan un enfoque social y una relevancia en la inclusión del ciudadano. Ejemplo de lo anterior, en el marco del encuentro Inteligencia Colectiva Bilbo (Zoohaus, 2012), se reflexionó sobre los desarrollos actuales en temas de participación, "es una nueva dimensión del procomún, bajo la forma de espacio urbano y edificaciones, aupada por el trabajo colectivo y liberada de buena parte de las obligaciones municipales centralizadas" (citado en Hernández Araque, 2014, p. 65). Lo anterior, a fin de utilizar esos nuevos movimientos crowd (multitud) como metodología para ejecutar proyectos y buscar soluciones inmediatas a falencias del espacio urbano actual.

Además de los nuevos movimientos crowd a los que se hizo referencia y los cuales tienen una resonancia importante en diferentes iniciativas y activistas urbanos, nuevos conceptos tales como la diplomacia pública —o capacidad de depositar en manos del ciudadano la gestión de sus propios intereses, escuchar sus comentarios, quejas o aportaciones y ponerlas en práctica en función de su mayoría; una democracia pública que deriva en buena parte del crowd power, estas-, hacen parte de las tendencias que comprueban la necesidad de nuevas metodologías para la construcción de un urbanismo incluyente, no solo para el uso de los espacios de la ciudad, sino en concepción y cocreación de la misma. "Hoy nos toca sumergirnos en el campo de la ciudad, desde lo social al citybranding, con el crowd como vía de expresión ciudadana y apropiación por parte de la ciudadanía, y desde iniciativas públicas, que muestran caminos que se están abriendo y alimentando con propuestas de participación ciudadana" (Cámara, 2012).

Chile es uno de los países que se ha interesado por el estudio de las tendencias en temas urbanos. En una de sus plataformas urbanas se dice:

En una época donde los ciudadanos chilenos se ven envueltos en una crisis de representación, en una desconfianza política generalizada y en mayores demandas y ambiciones, la sociedad últimamente ha manifestado una necesidad creciente de dar una vuelta en la manera de pensar y hacer ciudad, una forma mucho más descentralizada, inclusiva y representativa. Con esto, el urbanismo ha tendido a formular, cada vez más, modos de hacer proyectos "desde abajo hacia arriba", es decir, en vez de partir desde lo general a lo particular, partir desde la misma ciudadanía y sus demandas y necesidades (Castro, 2013, p. 4).
Desde otra perspectiva crítica, algunos encuentran al crowdsourcing como algo problemático, argumentando que la eficacia del sitio basado en el crowdsourcing está fuertemente ligada a su alcance. Muchos de los proyectos de diseño urbano favorecieron objetos y soluciones de pequeña escala — un programa para las bicicletas plegables, por ejemplo, o una aplicación móvil que pone en relieve opciones de aparcamientos cercanos, son unas de las propuestas bajo este modelo-. Esto nos puede dar una idea en cuanto al postulado de microproyectos que no serían problemáticos para nuestro contexto, en los cuales las microescalas en ocasiones son las que resultan dar megaproyectos, calificados así por su alto impacto social, más que por las majestuosidades de sus áreas de construcción o intervención.

Lo anterior es un aspecto que se tendrá en cuenta para el caso de esta investigación, ya que la propuesta se encamina en principio hacia la gestión urbana participativa de pequeños vacíos urbanos encontrados en sectores de mediana escala.

Existen proyectos urbanos que se han ejecutado bajo esta teoría del trabajo colectivo y se reflexiona al respecto según el caso; por ejemplo, NY busca ideas en el crowdsourcing para hacer la ciudad más habitable (Abad, 2011). En términos generales, el fundamento del proyecto es:

\footnotetext{
Hace tiempo que las empresas descubrieron la eficacia y rentabilidad del crowdsourcing. Les toca ahora a los gobiernos y en eso está, en la actualidad, la alcaldía de Nueva York. En mayo comenzará un programa destinado a escuchar las propuestas de los ciudadanos para mejorar la ciudad. Una vez se definan iniciativas por llevar a cabo serán los mismos ciudadanos los promotores y ejecutores de dichas iniciativas (Abad, 2011).
}

Caso parecido es el proyecto que se llama Bristol Rising y está llevándose a cabo en Bristol (Estados Unidos).

Imagina que los ciudadanos pueden proponer iniciativas para su ciudad en una página web. Que todos los ciudadanos pueden votar las propuestas tal como se hace en las redes sociales, apretando un ícono de "Me gusta" o comentando. Que después, la institución que gobierna la ciudad estudia las propuestas con más adhesiones y las ejecuta. No se trata de un sueño lejano (Gutiérrez, 2012).

Otro colectivo urbano que trabaja bajo la filosofía del crowdsourcing es 10.000 ideas, crowdsourcing para diseñar ciudades Latinoamericanas inteligentes ${ }^{8}$, el cual es un grupo creado para "conversar y pensar una ciudad construida desde las personas que la habitan" (Herrera, 2012).

8 http://pulsosocial.com/2012/03/13/10-000-ideas-crowdsourcing-para-disenar-ciudades-latinoamericanas-inteligentes-2/

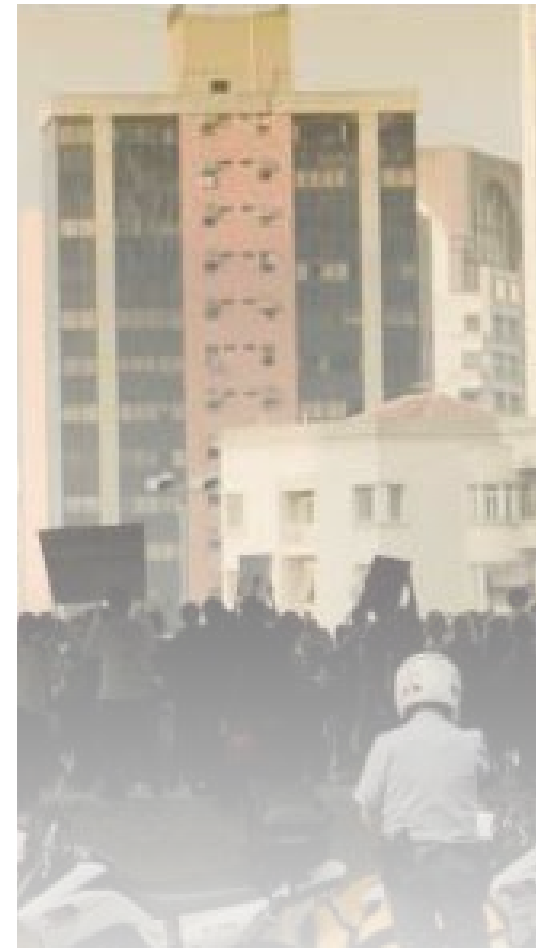




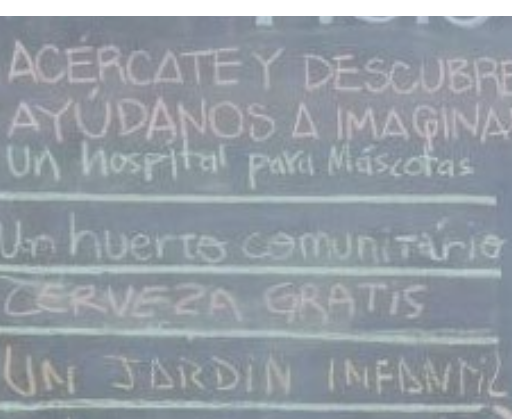

Este trabajo de participación colectiva referencia el concepto de smart city, que en la actualidad está a la vanguardia y con el cual introduce la importancia que tienen estas metodologías de participación ciudadana. Afirman que este concepto "vincula a pensar las ciudades desde las personas que las habitan, esto es, tomar la participación ciudadana, la transparencia y la colaboración para gestar verdaderas ciudades inteligentes, adaptadas a las culturas y usos que las atraviesan" (Herrera, 2012). Cifras divulgadas por ECOES 9 evidencian que:

...en el año 2050 el 70\% de la población mundial vivirá en núcleos urbanos; pensar en su futuro se vuelve entonces primordial. Desde la visión de innovación social vinculada a la Tecnología, un referente como Adam Greenfield (2010 citado en Herrera, 2012,) habla de necesitar herramientas que le den poder a los ciudadanos y no solamente hablar de administrar ciudades (p. 63)

De la mano con el crowdsourcing, existe un concepto que por la similitud de su significado y objetivo es preciso anotar, este es la inteligencia colectiva:

\begin{abstract}
...se refiere al levantamiento de datos, observaciones y necesidades hechos por los propios ciudadanos y no por un estudio de organizaciones o entes políticos. En este sentido, la noción de "colaboración" cobra fuerza al ser un medio de información que apela a la imaginación, necesidad y participación social, y que requiere maneras innovadoras y didácticas para facilitar, optimizar y masificar su uso (Echeverri, 2010).
\end{abstract}

A pesar de que la mayoría de los proyectos ejecutados por medio del modelo crowdsourcing tienen la herramienta web como la más utilizada, este modelo de participación colectiva permite idear herramientas complementarias que tienen como principio la interacción del ciudadano con el ciudadano, el vecino con el vecino y la del ciudadano-vecino con el territorio.

De esta forma, utilizando las herramientas del crowdsourcing, se intenta invitar a la comunidad a una participación colectiva en la creación de ciudades que deben estar preparadas para el futuro. Como señala el bloguero español Juan Freire (2012), especialista en temas urbanos: “Aunque no seamos conscientes nos conectamos emocionalmente con las ciudades, con los paisajes, con los países, a partir de la relación con las personas que pasan por nuestras vidas. Toda geografía es emocional" (p. 1).

9 Economía y desarrollo. Grupo que trabaja para conseguir el bienestar de todas las personas dentro de los límites de planeta. "Para ello buscamos cómplices entre la ciudadanía las organizaciones de la sociedad civil, las empresas y las administraciones públicas, para acelerar la transición a una economía verde, inclusiva y responsable, enmarcada en una nueva gobernanza, mediante la innovación y la creación de puentes y alianzas".
La filosofía del crowdsourcing se relaciona directamente con la concepción del urbanismo participativo, donde el ciudadano hace ciudad, el urbanismo se transforma a través de pequeñas acciones y el ciudadano encuentra una oportunidad para tener una verdadera participación y construcción de soluciones a sus necesidades.

Un referente más cercano a nuestra realidad en Colombia, que de alguna manera considera para la gestión de un urbanismo social los tres pilares que debe tener cualquier proyecto urbano —sociedad, institución y territorio-, son los conocidos proyectos urbanos integrales (PUI), que inició la Empresa de Desarrollo Urbano de Medellín en 2004. La filosofía de los PUI es generar proyectos de transformación urbana donde los habitantes locales de las zonas que se van a intervenir tienen una participación directa en el diagnóstico de la problemática y en el diseño de los proyectos a través de los conocidos talleres de diseño participativo. La repercusión que han tenido de manera general los proyectos ejecutados a través del instrumento PUI ha sido la concepción de espacios locales que suplen necesidades urbanas inmediatas y colectivas de los pobladores de las zonas, la apropiación de los espacios por los ciudadanos que se encargan en parte de su mantenimiento y sostenibilidad, y, lo más importante, ha logrado un impacto de cohesión social significativo, que es algo de lo que la ciudad estaba urgida. Ejemplos que tenemos a la orden del día y que se deben estudiar, entender y proyectar para hacer ciudades más incluyentes, participativas y atractivas para sus habitantes. Esta revisión teórica y conceptual es apenas el inicio de una investigación que pretende alcanzar escenarios reales, llevando la teoría a la praxis.

\section{CONCLUSIONES}

Los procesos de participación ciudadana desde los documentos normativos de la legislación colombiana, según el caso, dan cuenta del derecho que todos los ciudadanos tienen como agentes de voz y voto en los proyectos de transformación de la ciudad. Así, pues, es importante que la ciudadanía tome conciencia de la importancia de su opinión en los procesos que conllevan construir ciudad, pues al ser los principales usuarios de la misma, se convierten en la principal fuente de información en procesos de diagnosticar las necesidades de la ciudad y del ciudadano, además de ser los principales beneficiados o afectados por dichas intervenciones. 
A pesar de conocer la teoría legal de los derechos que se le asignan al ciudadano en los procesos de intervención del espacio urbano, se identifica la falta de veracidad en estos procesos, dado que la participación se ha reducido al procedimiento de informar al ciudadano de los planes y proyectos planteados, sin darle un espacio real para la expresión de sus ideas, opiniones y conceptos, y sin incluirlo en las etapas de formulación, diseño y ejecución de los proyectos que transforman, desarrollan y generan dinámicas en el entorno en el que convive.

Es necesario que, desde la teoría, los estudios técnicos y los espacios académicos del urbanismo, se empiecen a explorar nuevas alternativas para la construcción y transformación de la ciudad; procesos que utilicen metodologías de trabajo con la comunidad y construcción social del lugar, donde se establezca como objetivo principal el solucionar las necesidades de los habitantes.

El urbanismo participativo, como una de esas nuevas alternativas para la construcción social de la ciudad, es sin lugar a dudas un nuevo concepto de inclusión, de construcción colectiva y activismo, con el cual se puede conseguir transformar la ciudad para el ciudadano, a través de los proyectos a pequeña y mediana escala que están logrando un despertar de la ciudadanía, una participación colectiva de ciudad y una apropiación por parte del usuario de los espacios que le brindan oportunidades para la realización de los quehaceres de su cotidianidad.

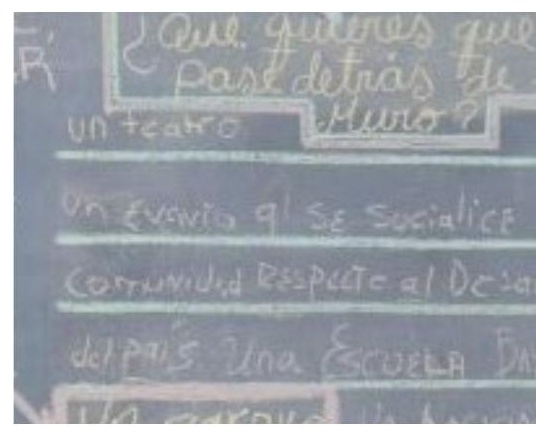

\section{REFERENCIAS}

Abad, N. (2011, 24 de enero). NY busca ideas en el crowd sourcing para hacer la ciudad más habitable. Recuperado de: http://www. yorokobu.es/ny-busca-ideas-en-el-crowdsourcing-para-hacer-la-ciudad-mas-habitable/

Cámara, C. (2012). Las iniciativas de participación ciudadana en el urbanismo. El urbanismo participativo, una nueva forma de entender la ciudad y la ciudadanía en la configuración de espacios públicos. Revista de estudios y Ciencias Sociales, 2 (1). 19-32. Recuperado de: https: //www.academia.edu/1532278/Las_iniciativas de participaci\%C3\%B3n ciudadana en el urbanismo. El urbanismo participativo_una_nueva_forma_de_entender_la_ciudad_y_la_ciudadan\%C3\%ADa en la configurāi\%C3\%B3n de espacios_p\% $\%$ C3\%BAblicos

Castro, A. (2013, 28 de agosto). Inteligencia colectiva y participación ciudadana. Plataforma Urbana. Recuperado de: http://www. plataformaurbana.cl/archive/2013/08/28/ inteligencia-colectiva-y-participacion-ciudadana/

Constitución Política de Colombia (1991, 20 de julio). Página oficial Senado de la República. Bogotá

Corredor, J. (2012). Participación ciudadana en renovación urbana en Bogotá. Resumen. X seminario de investigación urbana y regional.

Decreto distrital 448 (2007, 28 de septiembre). Por el cual se crea y estructura el Sistema Distrital de Participación Ciudadana. Alcaldía Mayor de Bogotá. Bogotá.

Di Sierna, D. (2012, 27 de septiembre) Urbanismo emergente, ciudadanía y esfera digital. Urbano Humano. Revista digital. Recuperado de: http://urbanohumano.org/castellano2/ urbanismo-emergente-ciudadania-y-esfera-digital/.

Echeverri Jiménez, C. F. (2010). La participación ciudadana en Colombia: reflexiones desde la perspectiva constitucional y la normatividad estatutaria. Estudios de Derecho, 67 (149), 61-86. Recuperado de: http://tesis.udea. edu.co/dspace/bitstream/10495/2284/1/ La\%20participaci\%C3\%B3n\%20ciudada- na\%20en $\% 20$ Colombia\%20reflexiones $\% 20$ desde\%20la\%20perspectiva\%20constitucional.pdf

Freire, J. (2012, 4 de febrero). Ausencia de sentido. Toda geografía es emocional. Recuperado de: http://juanfreire.tumblr.com/ post/17040699029/toda-geograf\%C3\% ADa-es-emocional

Freire, J. (2009). Urbanismo emergente: ciudad, tecnología e innovación social. Paisajes domésticos, redes de borde, 18-27.

Gaete Feres, H. (2005). Hacia un modelo de administración y gestión del urbanismo para ciudades intermedias. El caso del Gran Concepción en la Región del Bío-Bío, Chile. Universitat Politècnica de Catalunya. Departament de Construccions Arquitectòniques (Tesis). Recuperado http://www. tdr.cesca.es/handle/10803/6117; jsessionid =4D77DB25A876B582F9AD794A33DB6 7D3.tdx1

García J. y García D. (2005, 1 de septiembre). Scripta Nova. Propuesta para la configuración de una teoría general de la gestión urbanística. Recuperado de: http://www. ub.edu/geocrit/sn/sn-196.htm

Gutiérrez, B. (2012, 24 de junio) ¿Crowd funding para ciudades? 20minutos.es-Código abierto. Recuperado de: http://blogs.20minutos. es/codigo-abierto/2012/06/24/crowd-funding-para-ciudades/

Hernández Araque, M. J. (2014, agosto-diciembre). Construcción social de espacios urbanos bajo la metodología de gestión crowdsourcing. Arquitrabe, 5 (8). 60-72 Recuperado de: http://letravirtual.usbctg.edu.co/index.php/arquitrabe/article/ view/361/385

Herrera, C. (2012, 13 de marzo). 10.000 ideas crowdsourcing para diseñar ciudades inteligentes en Latinoamérica. Recuperado de http://10.000ideas.com/

Howe, J. (2006). The rise of crowdsourcing. Wired. Revista digital. Recuperado de: http://www.wired.com/2006/06/crowds/

Ley 388 (1997, 12 de septiembre). Por la cual se modifica la Ley 9a de 1989 y la Ley 3a de 1991 y se dictan otras disposiciones.
Diario oficial de la República de Colombia. Bogotá.

Ley 507 (1999, 28 de julio). Por la cual se modifica la Ley 388 de 1997. Diario oficial de la República de Colombia. Bogotá.

López Rangel, R. (2012). Las teorías urbanas, un tema transdisciplinario, no neutral. Catedra Sur: Universidad Autónoma Metropolitana y Universidad Nacional de General Sarmiento. Memorias. Recuperado de: http:// www.ungs.edu.ar/catedrasur/wp-content/ uploads/2012/11/3_LOPEZ-RANGEL_VF.pdf

Reyes, C. (2011, 29 de marzo). La ciudad viva. Urbanismo emergente o "Tactical Urbanism". Recuperado de: http://www.laciudadviva.org/blogs/?p=9651

Sentencia C-169/01 (2001, 14 de febrero). Corte constitucional de Colombia. Bogotá. Recuperado de: http://www.corteconstitucional.gov.co/relatoria/2001/C-169-01.htm

Sentencia C-179 (2002). Corte constitucional de Colombia. Bogotá. Recuperado de: http://corteconstitucional.gov.co/relatoria 002/C-179-02.htm

Steffens, K. (2014). Urbanismo táctico, 3 casos latinoamericanos. Ciudad emergente. Santiago: Fundación Ciudad Emergente. Recuperado de: http://www.ciudademergente. org/es/publicaciones/urbanismo-tacticov3-casos-latinoamericanos/

Subgerencia Cultural del Banco de la República (2015). Constitución Política de Colombia 1991. Participación ciudadana. Recuperado de: http://www.banrepcultural.org/blaavirtual/constitucion/participacion-ciudadana

Vergara Petrescu, J. (2013). ¿Qué es el urbanismo táctico? En Steffens, Kurt. Urbanismo Táctico 3. Casos Latinoamérica (pp. 13-17). Santiago de Chile: Fundación Ciudad Emergente. Recuperado de: http:// www.ciudademergente.org/es/publicaciones/urbanismo-tactico-v3-casos-latinoamericanos/

Zoohaus (2012, 26 de mayo). Inteligencia colectiva. Extra! IC Bilbo Meeting. Recuperado de: http://www.inteligenciascolectivas.org/ extra-ic-bilbo-meeting. 
La postulación de un artículo a la Revista de Arquitectura indica que- el o los autores certifican que conocen y aceptan la política editorial, para lo cual firmarán en original y remitirán el formato RevArq FP00 Carta de originalidad.

La Revista de Arquitectura maneja una política de Autoarchivo VERDE, según las directrices de SHERPA/RoMEO, por lo cual el autor puede:

Pre-print del autor: Archivar la versión pre-print (la versión previa a la revisión por pares)

Post-print del autor: Archivar la versión post-print (la versión final posterior a la revisión por pares)

Versión de editor/PDF: Archivar la versión del editor - PDF/HTML/XLM en la maqueta de la Revista de Arquitectura.

El Autoarchivo se debe hacer respetando la licencia de acceso abierto, la integridad y la imagen de la Revista de Arquitectura, también se recomienda incluir la referencia, el vínculo electrónico y el DOI.

El autor o los autores son los titulares del Copyright (c) del texto publicado y la Editorial de la Revista de Arquitectura solicita la firma de una autorización de reproducción del artículo (RevArq FP03 Autorización reproducción), la cual se acoge a la licencia CC, donde se expresa el derecho de primera publicación de la obra.

La Revista de Arquitectura se guía por las normas internacionales sobre propiedad intelectual y derechos de autor, y de manera particular el artículo 58 de la Constitución Política de Colombia, la Ley 23 de 1982 y el Acuerdo 172 del 30 de septiembre de 2010 (Reglamento de propiedad intelectual de la Universidad Católica de Colombia).

Para efectos de autoría y coautoría de artículos se diferencian dos tipos: "obra en colaboración" y "obra colectiva". La primera es aquella cuya autoría corresponde a todos los participantes al ser fruto de su trabajo conjunto. En este caso, quien actúa como responsable y persona de contacto debe asegurar que quienes firman como autores han revisado y aprobado la versión final, y dan consentimiento para su divulgación. La obra colectiva es aquella en la que, aunque participan diversos colaboradores, hay un autor que toma la iniciativa, la coordinación y realización de dicha obra. En estos casos, la autoría corresponderá a dicha persona (salvo pacto en contrario) y será suficiente únicamente con su autorización de divulgación.

El número de autores por artículo debe estar justificado por el tema, la complejidad y la extensión, y no deberá ser superior a la media de la disciplina, por lo cual se recomienda que no sea mayor de cinco. El orden en que se enuncien corresponderá a los aportes de cada uno a la construcción del texto, se debe evitar la autoría ficticia o regalada. Si se incluyen más personas que trabajaron en la investigación se sugiere que sea en calidad de colaboradores o como parte de los agradecimientos. La Revista de Arquitectura respetará el número y el orden en que figuren en el original remitido. Si los autores consideran necesario, al final del artículo pueden incluir una breve descripción de los aportes individuales de cada uno de firmantes.

La comunicación se establece con uno de los autores, quien a su vez será el responsable de informar a los demás autores de las notificaciones emitidas por la Revista de Arquitectura.

En virtud de mantener el equilibro de las secciones y las mismas oportunidades para todos los participantes, un mismo autor puede postular dos o más artículos de manera simultánea; si la decisión editorial es favorable y los artículos son aceptados, su publicación se realizará en números diferentes.

\section{(A) ACCESO ABIERTO}

La Revista de Arquitectura, en su misión de divulgar la investigación y apoyar el conocimiento y la discusión en los campos de interés, proporciona acceso abierto, inmediato e irrestricto a su contenido de manera gratuita mediante la distribución de ejemplares impresos y digitales. Los interesados pueden leer, descargar, guardar, copiar y distribuir, imprimir, usar, buscar o referenciar el texto completo o parcial de los artículos o la totalidad de la Revista de Arquitectura.

\section{(c) (1) (9)}

Esta revista se acoge a la licencia Creative Commons (CC BYNC de Atribución - No comercial 4.0 Internacional): "Esta licencia permite a otros entremezclar, ajustar y construir a partir de su obra con fines no comerciales, y aunque en sus nuevas creaciones deban reconocerle su autoría y no puedan ser utilizadas de manera comercial, no tienen que estar bajo una licencia con los mismos términos".

La Revista de Arquitectura es divulgada en centros y grupos de investigación, en bibliotecas y universidades, y en las principales facultades de Arquitectura, mediante acceso abierto a la versión digital y suscripción anual al ejemplar impreso o por medio de canje, este último se formaliza mediante el formato RevArq FP20 Canjes.

Para aumentar su visibilidad y el impacto de los artículos, se envían a bases de datos y sistemas de indexación y resumen (SIR) y, asimismo, pueden ser consultados y descargados en la página web de la revista.

La Revista de Arquitectura no maneja cobros, tarifas o tasas de publicación de artículo (Article Processing Charge-APC), o por el sometimiento de textos a la publicación.

\section{(1ÉTICA Y BUENAS PRÁCTICAS}

La Revista de Arquitectura se compromete a cumplir y respetar las normas éticas en todas las etapas del proceso de publicación. Los autores de los artículos publicados darán cumplimiento a los principios éticos contenidos en las diferentes declaraciones y legislaciones sobre propiedad intelectual y derechos de autor específicos del país donde se realizó la investigación. En consecuencia, los autores de los artículos postulados y aceptados para publicar, que presentan resultados de investigación, deben firmar la declaración de originalidad (formato RevArq FP00 Carta de originalidad).

La Revista de Arquitectura reconoce y adopta los principios de transparencia y buenas prácticas descritos por COPE, "Principles of Transparency and Best Practice in Scholarly Publishing" (2015).

El equipo editorial tiene la obligación de guardar la confidencialidad acerca de los artículos recibidos, y abstenerse de usar en sus propias investigaciones datos, argumentos o interpretaciones hasta tanto el artículo no sea publicado. También debe ser imparcial y gestionar los artículos de manera adecuada y en los plazos establecidos. La selección de revisores se hará con objetividad y estos deberán responder a la temática del artículo.

El editor, los autores y los revisores deben seguir las normas éticas internacionales definidas por el Committee on Publication Ethics (COPE), con el fin de evitar casos de:

- Fabricación, falsificación u omisión de datos.

- Plagio y autoplagio.

- Publicación redundante, duplicada o fragmentada.

- Omisión de referencias a las fuentes consultadas.

- Utilización de contenidos sin permiso o sin justificación.

- Apropiación individual de autoría colectiva.

- Cambios de autoría.

- Conflicto de interés (CDI) no revelado o declarado.

- Otras que pudieran surgir en el proceso de investigación y publicación. La fabricación de resultados se genera al mostrar datos inventados por los autores; la falsificación resulta cuando los datos son manipulados y cambiados a capricho de los autores; la omisión se origina cuando los autores ocultan deliberadamente un hecho o dato. El plagio se da cuando un autor presenta como ideas propias datos creados por otros. Los casos de plagio son los siguientes: copia directa de un texto sin entrecomillar o citar la fuente, modificación de algunas palabras del texto, paráfrasis y falta de agradecimientos; el autoplagio se da cuando el mismo autor reutiliza material propio que ya fue publicado, pero sin indicar la referencia al trabajo anterior. La revista se apoya en herramientas digitales que detectan cualquiera de estos casos en los artículos postulados, y es labor de los editores y revisores velar por la originalidad y fidelidad en la citación. La publicación redundante o duplicada se refiere a la copia total, parcial o alterada de un trabajo ya publicado por el mismo autor

En caso de sospechar de alguna mala conducta se recomienda seguir los diagramas de flujo elaborados por COPE (2008), con el fin de determinar las acciones correspondientes.

La Revista de Arquitectura se reserva el derecho de retractación de publicación de aquellos artículos que, posterior a su publicación, se demuestre que presentan errores de buena fe, o cometieron fraudes o malas prácticas científicas. Esta decisión se apoyará en "Retraction Guidelines" (COPE, 2009). Si el error es menor, este se podrá rectificar mediante una nota editorial de corrección o una fe de erratas. Los autores también tienen la posibilidad de solicitar la retractación de publicación cuando descubran que su trabajo presenta errores graves. En todos los casos se conservará la versión electrónica y se harán las advertencias de forma clara e inequívoca.

\section{A PRIVACIDAD Y MANEJO DE LA INFORMACIÓN.} HABEAS DATA

Para dar cumplimiento a lo previsto en el artículo 10 del Decreto 1377 de 2013, reglamentario de la Ley 1581 de 2012, y según el Acuerdo 002 del 4 de septiembre de 2013 de la Universidad Católica de Colombia, "por el cual se aprueba el manual de políticas de tratamiento de datos personales"

La Universidad Católica de Colombia, considerada como responsable o encargada del tratamiento de datos personales, manifiesta que los datos personales de los autores, integrantes de los comités y pares revisores, se encuentran incluidos en nuestras bases de datos; por lo anterior, y en cumplimiento de las disposiciones legales vigentes, la Universidad solicitará siempre su autorización, para que en desarrollo de sus funciones propias como Institución de Educación Superior, en especial las relacionadas con la docencia, la extensión y la investigación, la Universidad Católica de Colombia pueda recolectar, recaudar, almacenar, usar, circular, suprimir, procesar, intercambiar, compilar, dar tratamiento, actualizar, transmitir o transferir a terceros países y disponer de los datos que le han suministrado y que han sido incorporados en las bases de datos de todo tipo que reposan en la Universidad.

La Universidad Católica de Colombia queda autorizada, de manera expresa e inequívoca, en los términos señalados por el Decreto 1377 de 2013, para mantener y manejar la información de nuestros colaboradores (autores, integrantes de los diferentes comités y pares revisores); así mismo, los colaboradores podrán ejercer sus derechos a conocer, actualizar, rectificar y suprimir sus datos personales, para lo cual se han dispuesto las siguientes cuentas de correo electrónico: 
La Revista de Arquitectura recibe artículos de manera permanente. Los artículos se procesan a medida que se postulan, dependiendo el flujo editorial de cada sección.

El idioma principal es el español, y como opcionales están definidos el inglés, el portugués y el francés; los textos pueden ser escritos y presentados en cualquiera de estos.

Los artículos postulados deben corresponder a las categorías universalmente aceptadas como producto de investigación, ser originales e inéditos y sus contenidos responder a criterios de precisión, claridad y brevedad.

Como punto de referencia se pueden tomar las tipologías y definiciones del Índice Bibliográfico Nacional, Publindex (2010) que se describen la continuación:

1. Artículo de revisión: documento resultado de una investigación terminada donde se analizan, sistematizan e integran los resultados de investigaciones publicadas o no publicadas, sobre un campo en ciencia o tecnología, con el fin de dar cuenta de los avances y las tendencias de desarrollo. Se caracteriza por presentar una cuidadosa revisión

bibliográfica de por lo menos 50 referencias.
2. Artículo de investigación científica y tecnológica: documento que presenta, de manera detallada, los resultados originales de proyectos terminados de investigación. La estructura generalmente utilizada contiene cuatro apartes importantes: introducción, metodología, resultados y conclusiones.

3. Artículo de reflexión: documento que presenta resultados de investigación terminada desde una perspectiva analítica, interpretativa o crítica del autor, sobre un tema específico, recurriendo a fuentes originales.

En todos los casos se debe presentar la información suficiente para que cualquier investigador pueda reproducir la investigación y confirmar o refutar las interpretaciones defendidas.

También se pueden presentar otro tipo de documentos diferentes a los anteriormente descritos, como pueden ser: artículo corto, reporte de caso, revisión de tema, documento resultado de la revisión crítica de la literatura sobre un tema en particular, cartas al editor, traducción, documento de reflexión no derivado de investigación, reseña bibliográfica, así como proyectos de arquitectura o urbanismo, entre otros

\section{A INSTRUCCIONES PARA POSTULAR ARTÍCULOS}

Postular el artículo en la página web de la Revista de Arquitectura y adjuntar comunicación escrita dirigida al editor RevArq_FP00 Carta de originalidad (debidamente firmada por todos los autores en original); de igual manera, se debe diligenciar el formato de hoja de vida RevArq FP01 Hoja de Vida (una por cada autor).

En la comunicación escrita el autor expresa que conoce y acepta la política editorial de la Revista de Arquitectura, que el artículo no está postulado para publicación simultáneamente en otras revistas u órganos editoriales y que no existe conflicto de intereses (ver modelo RevArq FP06 CDI) y que, de ser aceptado, concederá permiso de primera publicación, no exclusiva a nombre de la Universidad Católica de Colombia como editora de la revista.

Los artículos deben tener en cuenta las siguientes recomendaciones:

- En la primera página del documento se debe incluir:

TítUlo: no exceder 15 palabras.

Subtítulo: opcional, complementa el título o indica las principales subdivisiones del texto.

NOMBRE DEL AUTOR O AUTORES: nombres y apellidos completos o según modelo de citación adoptado por el autor para la normalización de los nombres del investigador. Como nota al pie (máximo 150 palabras): formación académica, experiencia profesional e investigativa, vinculación laboral, premios o reconocimientos, publicaciones representativas e información de contacto, correo electrónico.

FILIACIÓN INSTITUCIONAL: debajo del nombre se debe declarar la inV titución en la cual se desarrolló el producto, de la cual recibió apoyo o aquella que respalda el trabajo investigativo.

RESUMEN: debe ser analítico, se redacta en un solo párrafo, da cuenta del tema, el objetivo, la metodología, los resultados y las conclusiones; no debe exceder las 150 palabras.

PALABRAS CLAVE: cinco palabras o grupo de palabras, ordenadas alfabéticamente y que no se encuentren en el título o subtítulo; estas sirven para clasificar temáticamente al artículo. Se recomienda emplear principalmente palabras definidas en el tesauro de la Unesco (http:// databases.unesco.org/thessp/) o en el tesauro de Arte \& Arquitectura (C) (www.aatespanol.cl).

También se recomienda incluir título, resumen y palabras clave en segundo idioma.

- La segunda página y siguientes deben tener en cuenta:

El cuerpo del artículo generalmente se divide en: Introducción, Metodología, Desarrollo, Resultados y Discusión de resultados; posteriormente se presentan las Conclusiones, y luego las Referencias bibliográficas y los Anexos (método IMRYD). Las tablas y figuras se deben incorporar en el texto.

DESCRIPCIÓN DEL PROYECTO DE INVESTIGACIÓN: en la introducción se debe describir el tipo de artículo y brevemente el marco investigativo del cual es resultado y diligenciar el formato (RevArq FP02 Info Proyectos de Investigación).

TEXTO: todas las páginas deben venir numeradas y con el título de artículo en la parte inferior (pie de página). Márgenes de $3 \mathrm{~cm}$ por todos los lados, interlineado doble, fuente Arial o Times New Roman de 12 puntos, texto justificado (Ver plantilla para presentación de artículos). La extensión de los artículos debe ser de alrededor de 5.000 palabras ( \pm 20 páginas, incluyendo gráficos, tablas, referencias, etc.); como mínimo 3.500 y máximo 8.000 palabras. Se debe seguir el estilo vigente y recomendado en el Manual para Publicación de la American Psychological Association (APA). (Para mayor información véase http://www.apastyle.org/)
CITAS Y NOTAS AL PIE: las notas aclaratorias o notas al pie no deben exceder cinco líneas o 40 palabras, de lo contrario estas deben ser incorporadas al texto general. Las citas pueden ser:

Corta: (con menos de 40 palabras) se incorporan al texto y pueden ser: textuales (se encierran entre dobles comillas), parafraseo o resumen (se escriben en palabras del autor dentro del texto).

Cita textual extensa: (mayor de 40 palabras) debe ser dispuesta en un renglón y un bloque independiente con sangrías y omitiendo las comillas, no olvidar en ningún caso la referencia del autor (Apellido, año, página).

REFERENCIAS: como modelo para la construcción de referencias se emplea el estilo recomendado en el Manual para Publicación de la American Psychological Association (APA) (http://www.apastyle.org/).

SIGLAS: en caso de emplear siglas en el texto, las figuras o las tablas, se debe proporcionar la equivalencia completa la primera vez que se empleen y encerrarlas entre paréntesis. En el caso de citar personajes reconocidos se deben colocar nombres o apellidos completos, nunca emplear abreviaturas.

GRÁFICOS Y TABLAS: las figuras (gráficos, diagramas, ilustraciones, planos, mapas o fotografías) y las tablas deben ir numeradas y contene título o leyenda explicativa relacionada con el tema del artículo, que no exceda las 15 palabras (Figura 1. xxxxx, Tabla 1. xxxx, etc.) y la procedencia (fuente: autor o fuente, año, página). Estas se deben citar en e texto de forma directa o entre paréntesis; se recomienda hacerlo con referencias cruzadas.

También se deben entregar en medio digital, independiente del texto, en formatos editables o abiertos. La marcación de los archivos debe corresponder a la incluida en el texto. Según la extensión del artículo se deben incluir de 5 a 10 gráficos. Ver guía para la búsqueda de imágenes de dominio público o bajo licencias Creative Commons (CC).

El autor es el responsable de adquirir los derechos o las autorizaciones de reproducción a que haya lugar para imágenes o gráficos tomados de otras fuentes, así como de entrevistas o material generado por colaboradores diferentes a los autores; de igual manera, se debe garantizar la protección de datos e identidades para los casos que sea necesario.

FOTOGRAFíA: pueden ser entregadas en original para ser digitalizadas, de lo contrario se deben digitalizar con una resolución igual o superior a 300 dpi para imágenes a color y 600 para escala de grises. Los formatos de las imágenes pueden ser TIFF, PSD o JPG, y deben cumplir con las características expresadas en el punto anterior (gráficos).

PLANIMETRÍA: se debe entregar la planimetría original en medio digital en lo posible en formato CAD, y sus respectivos archivos de plumas o en PDF; de no ser posible, se deben hacer impresiones en tamaño carta con las referencias de los espacios mediante numeración y lista adjunta. Deben tener escala gráfica, escala numérica, norte, coordenadas y localización. En lo posible, no deben contener textos, achurados o tramas.

Para más detalles, consultar el documento RevArq Parámetros para Autores Descripción en el portal web de la Revista de Arquitectura

\section{Beneficios}

Como reconocimiento a los autores, se les hará envío postal de dos ejemplares de la edición impresa sin ningún costo y entregada en la dirección consignada en el formato de hoja de vida (RevArq FP01); adicionalmente, se enviará el vínculo para la descarga de la versión digital.

También se enviará una constancia informativa en la que se relaciona la publicación del artículo y, de manera opcional, se pueden detallar las fechas del proceso editorial y el arbitraje realizado. 
La selección de revisores se realiza de acuerdo con los siguientes criterios:

- Afinidad temática.

- Formación académica.

- Experiencia investigativa y profesional.

- Producción editorial en revistas similares o en libros resultado de investigación.

El proceso de arbitraje se basa en los principios de equidad e imparcialidad, y en los criterios de calidad y pertinencia.

El desarrollo de la revisión se realiza según el formato (RevArq FP10 Evaluación de artículos) y las observaciones que el revisor considere necesarias en el cuerpo del artículo. En cualquiera de los conceptos que emita el revisor (Aceptar, Publicable con modificaciones, Reevaluable o No publicable), y como parte de la labor formativa y de comunidad académica, el revisor hará sugerencias para mejorar el documento. El revisor podrá solicitar una nueva relectura del artículo después de los ajustes realizados por el autor.

El revisor también deberá diligenciar el formato RevArq FP01 Hoja de Vida, con el fin de certificar y soportar el proceso de revisión ante los SIR que así lo soliciten.

En el proceso de arbitraje se emplea el método doble ciego, los nombres del revisor no serán conocidos por el autor y viceversa. Con el fin de garantizar el anonimato del autor, al artículo postulado se le han podido suprimir nombres, instituciones o imágenes que puedan ser asociadas de manera directa al autor.

Aunque se procura el anonimato, una vez recibida la invitación como par revisor del artículo, el revisor debe cerciorarse de que no exista conflicto de intereses (CDI) o alguna limitante que afecte la revisión o que pueda ser vista como tal (lazos familiares, amistad o enemistad, vínculos contractuales o laborales, posiciones éticas, etc.), de presentarse esta situación se notificara al editor. (Ver modelo RevArq FP06 CDI).

Dada la confidencialidad del proceso de revisión, y considerando los derechos de autor y de propiedad intelectual que pueda haber sobre el material que se entrega, el revisor se compromete a mantener en absoluta reserva su labor, a limitar el uso de la obra entregada solo para el propósito designado y a devolver la documentación remitida una vez concluya la actividad.

El tiempo establecido para las revisiones de pares es de máximo un mes a partir de la confirmación de la recepción de la documentación. Ese plazo podrá ser modificado de mutuo acuerdo entre el editor y el revisor, siempre y cuando no afecte la periodicidad de la revista, la impresión o el tiempo para emitir una respuesta al autor. Los revisores se acogerán a "COPE Ethical Guidelines for Peer Reviewers" de COPE.

\section{Beneficios}

Como retribución a los revisores se les hará envío postal de un ejemplar de la edición impresa sin ningún costo y entregada en la dirección consignada en el formato de hoja de vida. También, si es de interés para el revisor, podrá hacer la solicitud de alguna de las publicaciones editadas y presentes en el catálogo de publicaciones de la UNIVERSIDAD Católica de Colombia, previa aprobación de la Editorial y sujeto a la disponibilidad.

Si lo desea tendrá derecho a una constancia de la colaboración en la revisión de artículos, la cual solo contendrá el periodo en el cual se realizó la actividad. También tendrá la posibilidad de aceptar o no la publicación de su nombre, nacionalidad y nivel máximo de formación en la página web de la Revista de Arquitectura en su calidad de colaborador.

\section{(A) PROCESO DE REVISIÓN POR PARES}

Luego de la postulación del artículo, el editor de la Revista de Arquitectura selecciona y clasifica los artículos que cumplen con los requisitos establecidos en las directrices para los autores. El editor podrá rechazar en primera instancia artículos, sin recurrir a un proceso de revisión, si los considera de baja calidad o por presentar evidencias de faltas éticas o documentación incompleta.

Los artículos se someterán a un primer dictamen del editor, de los editores de sección y del Comité Editorial, teniendo en cuenta:

- Afinidad temática, relevancia del tema y correspondencia con las secciones definidas.

- Respaldo investigativo.

- Coherencia en el desarrollo del artículo, así como una correcta redacción y ortografía.
- Relación entre las figuras y tablas con el texto del artículo.

En esta revisión se verificará el nivel de originalidad mediante el uso de software especializado (Ithenticate o similar) y recursos digitales existentes para tal fin, también se observará la coherencia y claridad en los apartados del documento (método IMRYD), la calidad de las fuentes y la adecuada citación, esto quedará consignado en el formato (RevArq FP09 Revisión de artículos); esta información será cargada a la plataforma de gestión editorial y estará a disposición del autor.

En caso de que el artículo requiera ajustes preliminares, será devuelto al autor antes de ser remitido a revisores. En este caso, el autor tendrá veinte días para remitir nuevamente el texto con los ajustes solicitados.

Después de la preselección se asignan mínimo dos revisores especializados, quienes emitirán su concepto utilizando el formato (RevArq FP10 Evaluación de artículos) y las anotaciones que consideren oportunas en el texto; en esta etapa se garantizará la confidencialidad y el anonimato de autores y revisores (modalidad doble ciego).

Del proceso de revisión se emite uno de los siguientes conceptos que será reportado al autor:

- Aceptar el envío: con o sin observaciones.

- Publicable con modificaciones: se podrá sugerir la forma más adecuada para una nueva presentación, el autor puede o no aceptar las observaciones según sus argumentos. Si las acepta, cuenta con quince días para realizar los ajustes pertinentes.

- Reevaluable: cumple con algunos criterios y debe ser corregido. Es necesario hacer modificaciones puntuales y estructurales al artículo. En este caso, el revisor puede aceptar o rechazar hacer una nueva lectura del artículo luego de ajustado.

- No publicable: el autor puede volver a postular el artículo e iniciar nuevamente el proceso de arbitraje, siempre y cuando se evidencien los ajustes correspondientes.

En el caso de presentarse diferencias sustanciales y contradictorias en los conceptos sobre la recomendación del revisor, el editor remitirá el artículo a un revisor más o a un miembro del Comité Editorial quien podrá actuar como tercer árbitro, con el fin de tomar una decisión editorial sobre la publicación del artículo.

Los autores deberán considerar las observaciones de los revisores o de los editores, y cada corrección incorporada u omitida debe quedar justificada en el texto o en una comunicación adjunta. En el caso que los autores omitan las indicaciones realizadas sin una argumentación adecuada, el artículo será devuelto y no se dará por recibido hasta que no exista claridad al respecto.

El editor respetará la independencia intelectual de los autores y a estos se les brindará el derecho de réplica en caso de que los artículos hayan sido evaluados negativamente y rechazados.

Los autores, con su usuario y contraseña, podrán ingresar a la plataforma de Gestión Editorial, donde encontrarán los conceptos emitidos y la decisión editorial sobre el artículo.

El editor y el Comité Editorial se reservan el derecho de aceptar o no la publicación del material recibido. También se reservan el derecho de sugerir modificaciones de forma, ajustar las palabras clave o el resumen y de realizar la corrección de estilo. El autor conocerá la versión final del texto antes de la publicación oficial del mismo.

Cuando un artículo es aceptado para su publicación, el auto debe firmar la autorización de reproducción (RevArq FP03 Autorización reproducción). Para más información ver: Política de derechos de autor

\section{Notas aclaratorias:}

La Revista de Arquitectura publica un número limitado de artículos por volumen y busca el equilibrio entre las secciones, motivo por el cual, aunque un artículo sea aceptado o continúe en proceso de revisión, podrá quedar aplazado para ser publicado en un próximo número; en este caso, el autor estará en la posibilidad de retirar la postulación del artículo o de incluirlo en el banco de artículos del próximo número.

El editor y los editores de sección de la Revista de Arquitectura son los encargados de establecer contacto entre los autores y revisores, ya que estos procesos se realizan de manera anónima.

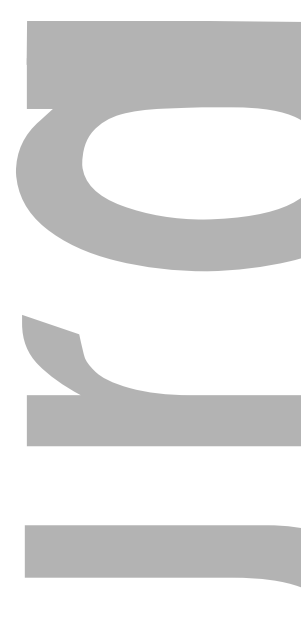

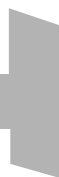
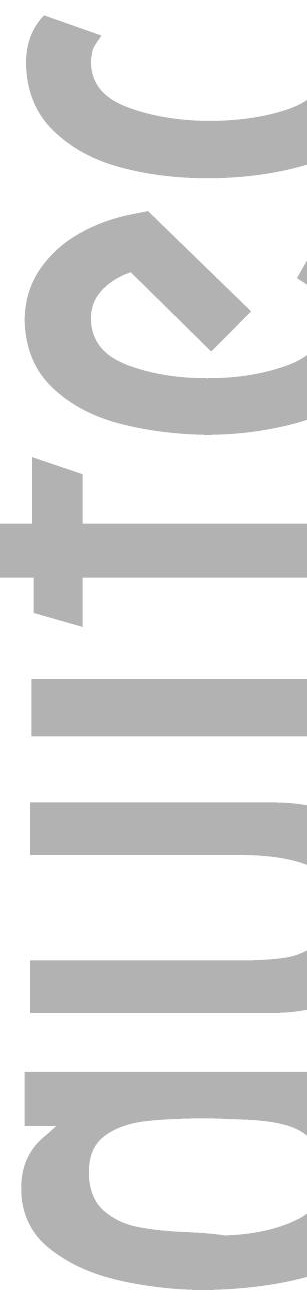

(2)

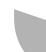

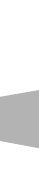

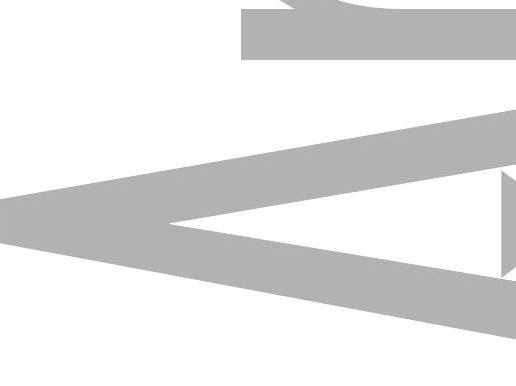


THE SOCIAL REPRESENTATION OF PUBLIC SPACE FOR THE DESIGN AND

MANAGEMENT OF SUSTAINABLE TERRITORIES

A THEORETICAL-PRACTICAL AND METHODOLOGICAL PROPOSAL FOR

PARTICIPATORY PLANNING

\section{Heidi Natalie Contreras-Lovich}

\section{PROPUESTA DE UN SISTEMA DE INDICADORES PARA EVALUAR}

PROPOSAL FOR A SYSTEM OF INDICATORS TO ASSESS THE VISUAL QUALITY OF

THE URBAN LANDSCAPE IN INFORMAL SETTLEMENTS

Johana Andrea Mesa Carranza, OsWaldo López Bernal.

Adriana Patricia López Valencia

Segregación EN EL ESPACIO URBANO de SOACHA

¿TRANSMILENIO COMO HERRAMIENTA INTEGRADORA?

SEGREGATION IN THE URBAN SPACE OF SOACHA

TRANSMILENIO AS AN INTEGRATING TOOL?

CARLos Augusto Moreno-Luna

\section{AROUITETURA E INDUSTRIALIZAÇÃO DAS CONSTRUÇÕES NA}

obra de JoÃo Filgueiras LIMA — LELÉ

ARCHITECTURE AND CONSTRUCTION'S INDUSTRIALIZATION IN THE WORK OF

JoĀo FilgueIrAs LIMA - LELÉ

Elza-Luli Miyasaka, Marieli Lukiantchuki, Michele C. B. Ferrari

CAIXETA, Marcio-Minto Fabricio

\section{EL DISEÑO DE LA VIVIENDA DE INTERÉS SOCIAL}

LA SATISFACCIÓN DE LAS NECESIDADES Y EXPECTATIVAS DEL USUARIO

THE DESIGN OF SOCIAL HOUSING

MEETING THE NEEDS AND USER EXPECTATIONS

Alex Leandro Pérez-PÉrez

EXPLORACIONES MORFOLÓGICAS EN TEXTURAS MODULARES

APROXIMACIONES DESDE EL OBJET TROUVÉ AL DISEÑO

نं PARAMÉTRICO

MORPHOLOGICAL EXPLORATIONS IN MODULAR TEXTURES

APPROXIMATIONS FROM OBJET TROUVÉ TO THE PARAMETRIC DESIGN

\section{CONSTRUCCIÓN EXPERIMENTAL DE UN SISTEMA}

